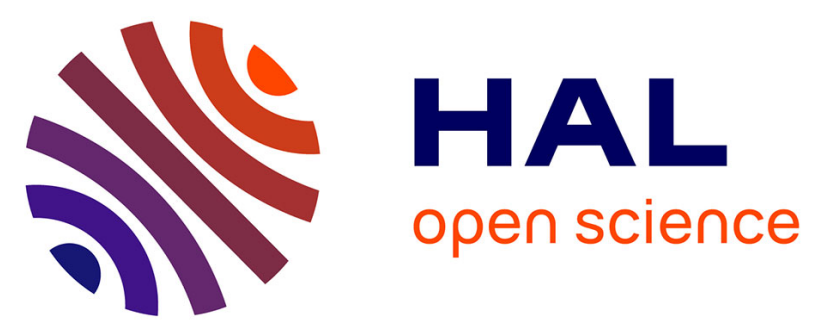

\title{
Tuning morphology of Pickering emulsions stabilised by biodegradable PLGA nanoparticles: How PLGA characteristics influence emulsion properties
}

Baptiste Robin, Claire Albert, Mohamed Beladjine, François-Xavier Legrand, Sandrine Geiger, Laurence Moine, Valérie Nicolas, Alexis Canette, Michaël Trichet, Nicolas Tsapis, et al.

\section{To cite this version:}

Baptiste Robin, Claire Albert, Mohamed Beladjine, François-Xavier Legrand, Sandrine Geiger, et al.. Tuning morphology of Pickering emulsions stabilised by biodegradable PLGA nanoparticles: How PLGA characteristics influence emulsion properties. Journal of Colloid and Interface Science, 2021, 595, pp.202-211. 10.1016/j.jcis.2021.03.061 . hal-03209750

\section{HAL Id: hal-03209750 \\ https://hal.sorbonne-universite.fr/hal-03209750}

Submitted on 12 Nov 2021

HAL is a multi-disciplinary open access archive for the deposit and dissemination of scientific research documents, whether they are published or not. The documents may come from teaching and research institutions in France or abroad, or from public or private research centers.
L'archive ouverte pluridisciplinaire HAL, est destinée au dépôt et à la diffusion de documents scientifiques de niveau recherche, publiés ou non, émanant des établissements d'enseignement et de recherche français ou étrangers, des laboratoires publics ou privés. 


\title{
Tuning morphology of Pickering emulsions stabilised by biodegradable PLGA nanoparticles: how PLGA characteristics influence emulsion properties
}

\author{
Baptiste Robin ${ }^{1}$, Claire Albert ${ }^{1}$, Mohamed Beladjine ${ }^{1}$, François-Xavier Legrand ${ }^{1}$, \\ Sandrine Geiger ${ }^{1}$, Laurence Moine ${ }^{1}$, Valérie Nicolas ${ }^{2}$, Alexis Canette ${ }^{3}{ }^{3}$ Michaël Trichet $^{3}$, Nicolas Tsapis ${ }^{1}$, \\ Florence Agnely ${ }^{1 \dagger}$, Nicolas Huang ${ }^{1{ }^{1}}$ \\ ${ }^{1}$ Université Paris-Saclay, CNRS, Institut Galien Paris-Saclay, 92296, Châtenay-Malabry, France \\ ${ }^{2}$ Microscopy facility (MIPSIT), Ingénierie et Plateformes au Service de l'Innovation Thérapeutique - IPSIT - UMS - \\ US31 - UMS3679 (IPSIT), Université Paris-Saclay, Châtenay-Malabry, France \\ ${ }^{3}$ Sorbonne Université, CNRS, Institut de Biologie Paris-Seine (IBPS), Service de microscopie électronique (IBPS- \\ SME), F-75005, Paris \\ ${ }^{\dagger}$ Same contribution \\ *Corresponding author: N. Huang, nicolas.huang@universite-paris-saclay.fr
}

\section{Abstract}

In this study, we proved that the stabilisation of Pickering emulsions by polymer nanoparticles (NPs) heavily depends on polymer characteristics. We prepared NPs with four poly(lactide-co-glycolide) polymers (PLGA), of different molar masses $(14,000$ and $32,000 \mathrm{~g} / \mathrm{mol})$ and end groups (acid or alkylester). NPs were either bare (without stabilising polymer) or covered by polyvinyl alcohol (PVA). Pickering emulsions were prepared by mixing NP aqueous suspensions with various amounts of oil (Miglyol 812N). First, NP wettability was directly affected by PLGA end group: ester-ending PLGA led to more hydrophobic NPs, compared to acid-ending PLGA. This effect of the end group could be slightly enhanced with smaller molar mass. Thus, bare PLGA NPs stabilised different types of emulsions (W/O/W and W/O), following Finkle's rule. However, the effect of PLGA characteristics was masked when NPs were covered by PVA, as PVA drove the stabilisation of O/W emulsions. Secondly, PLGA molar mass and end group also influenced its glass transition temperature $\left(T_{g}\right)$, with spectacular consequences on emulsion formation. Indeed, the shortest ester-ending PLGA exhibited a $T_{g}$ close to room temperature, when measured in the emulsion. This $T_{g}$, easily exceeded during emulsification process, led to a soft solid emulsion, stabilised by a network of NP debris.
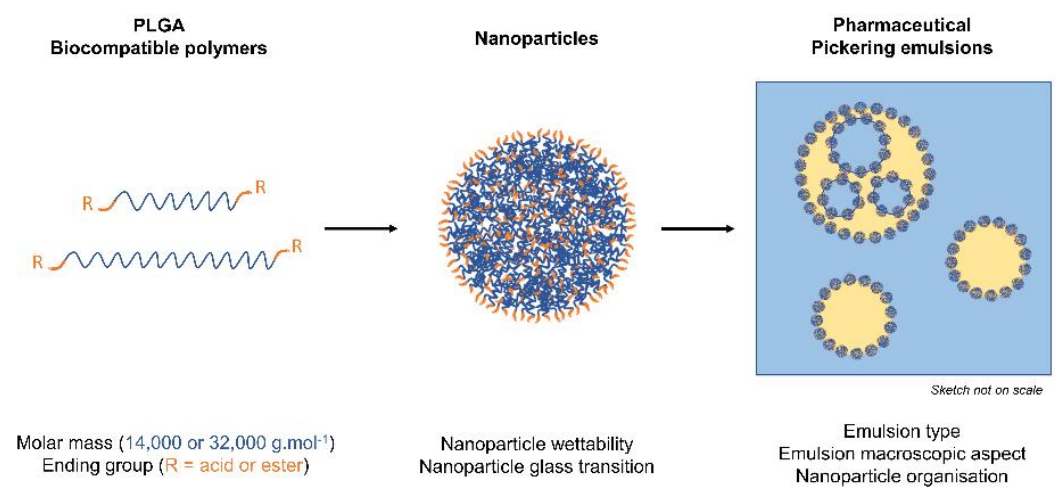

Keywords: Pickering emulsions, PLGA, nanoparticles, polymer end group, molar mass, PVA, wettability, glass transition temperature, emulsion type, nanoparticle organisation 
List of abbreviations:

CLSM: Confocal Laser Scanning Microscopy

CryoSEM: Scanning Electron Cryo-Microscopy

DSC: Differential Scanning Calorimetry

GA: Glycolic acid

LA: Lactic acid

NMR: Nuclear magnetic resonance

$\mathrm{NP}(\mathrm{s})$ : Nanoparticle(s)

O/W: Oil-in-Water

PLGA: Poly(Lactide-co-Glycolide)

PMMA: Poly(Methyl Methacrylate)

PVA: Poly(Vinyl Alcohol)

SEC: Size Exclusion Chromatography

TEM: Transmission Electronic Microscopy

$\mathrm{T}_{\mathrm{g}}$ : Glass transition temperature

W/O: Water-in-Oil

W/O/W: Water-in-Oil-in-Water 


\section{Introduction}

Some types of colloidal particles show great affinity for fluid-fluid interfaces. Partially wetted by the two fluids, they allow the preparation of very stable emulsions (called Pickering emulsions). For large particles equally wetted by water and oil, the energy of attachment can be several orders of magnitude larger than the thermal energy $k T$. In such a case, the adsorption is considered as irreversible [1,2]. Thus, particles form a physical barrier around the droplets, making the emulsions stable towards coalescence [3]. Besides their stability, Pickering emulsions are of great interest for pharmaceutical purposes, as they allow the reduction of surfactant use. Indeed, surfactants can induce irritations after repeated topical applications $[4,5]$, and alternative solutions must be found to avoid skin toxicity in long-term treatments.

In a previous work, we have demonstrated the interest of using poly(lactide-co-glycolide) (PLGA) nanoparticles (NPs) as stabilisers for Pickering emulsions [6]. PLGA is one of the most attractive polymer for the formulation of biocompatible pharmaceutical systems [7,8]. Various types of drug delivery systems based on PLGA have been formulated such as microparticles [9], nanoparticles [10] or implants [11,12]. They are intended for various applications such as tissue engineering [13], vaccines [14], antitumoral drug delivery [15], protein delivery [16], or siRNA delivery [17]. They allow, for example, to control or sustain the release (from days to weeks), to reduce dosage, to minimize side effects and to protect an encapsulated substance from degradation [18]. Some of them are already on the market, mostly for the controlled release of encapsulated proteins or peptides [19].

Composed of lactic acid (LA) and glycolic acid (GA) units linked together by ester bonds, it can be hydrolysed, leading to the polymer degradation [20]. The degradation kinetics modulation is a way to control the drug release, and it can be done by tuning the structure of PLGA. Various types of PLGA are available on the market, with very different characteristics. For instance, intermediate $L A / G A$ ratios [21,22] and racemic forms of PLGA [23] promotes the amorphous state of the matrix, increasing its degradation rate. Conversely, the degradation time can be extended by using high molar mass PLGA [24] or hydrophobic PLGA with a high content of LA $[21,24]$.

However, if changing the PLGA characteristics is interesting to control its degradation, it can also impact the physico-chemical properties of PLGA NPs. This, in turn, can alter the behaviour of Pickering emulsions stabilised by these NPs. Indeed, many studies have enlightened the influence of the NP surface properties on the emulsion morphology and stability [25]. Silica NPs are probably the most studied particles [26-30], but many other tuneable materials have also been studied such as clays [29,31], solid lipid NPs [32], polymeric NPs [33], etc. However, the influence of the PLGA characteristics on NP properties has rarely been described. To the best of our knowledge, only the impact of PLGA molar mass on Pickering emulsion stability has been assessed [34]. The influence of the PLGA end group or the influence of the stabilizing polymer has never been investigated.

Therefore, we designed a thorough study of the influence of PLGA molar mass and end group, as well as PVA-coverage, on the NP properties. Four different PLGA polymers with two different 
molar masses $(14,000$ and $32,000 \mathrm{~g} / \mathrm{mol})$ and two different end groups (acid or ester) were used. Depending on the preparation process, the resulting NPs were either bare (PLGA NPs) or covered by polyvinyl alcohol (PLGA-PVA NPs). Five different types of NPs were obtained and characterised in size, zeta potential, and glass transition temperature $\left(T_{g}\right)$. Their wettability was also evaluated by the sessile drop method, performed on PLGA films and NP tablets. Then, the particles were used to prepare emulsions with water and Miglyol $812 \mathrm{~N}$, a pharmaceutical oil (Miglyol $812 \mathrm{~N}$ ). The resulting Pickering emulsions were characterised at both macroscopic and microscopic scales, in terms of emulsion type and NP interfacial organisation. The characterisation of the NPs allowed us to explain the mechanisms of emulsion stabilisation, highlighting the great influence of the PLGA molar mass and end group, as well as the influence of the PVA-coverage, on the Pickering emulsions properties.

\section{Material and Methods}

\subsection{Material}

Four types of poly(D,L-lactide-co-glycolide) polymers were obtained from Evonik (Germany), all with a lactic acid:glycolic acid ratio (LA:GA) of 75:25: Resomer ${ }^{\circledR}$ RG 753 S (batch 1044590), $753 \mathrm{H}$ (batch D170100503), $752 \mathrm{~S}$ (batch R140400507) and $752 \mathrm{H}$ (batch D150800567). PLGA-rhodamine $B$ conjugate (LA:GA ratio of $50: 50, M_{w}=10,000-30,000 \mathrm{~g} / \mathrm{mol}$ ) was purchased from Akina Inc. (USA). Poly(vinyl alcohol) (PVA, $M_{w}=30,000-70,000 \mathrm{~g} / \mathrm{mol}, \quad 87-90 \%$ hydrolysed) was provided by Sigma-Aldrich (Germany). Miglyol 812N ( $\eta=30 \mathrm{mPa} . \mathrm{s}$, Newtonian), a medium chain triglyceride oil, was obtained from Cremer (Netherlands). Calcein and deuterium oxide came from Sigma-Aldrich (Germany). All the solvents (acetonitrile, acetone, dichloromethane, deuterated chloroform) were purchased at the highest grade from Carlo Erba (Italy). Water was purified (resistivity of $18.2 \mathrm{M} \Omega . \mathrm{cm}$ ) using a water system ultrapure MilliQ Direct Type 1 (Millipore, Germany).

\subsection{Polymer characterisation}

The molar mass of each polymer used to prepare PLGA and PLGA-PVA NPs was assessed by size exclusion chromatography (SEC, Tosoh EcoSEC HLC-8320 GPC, Japan) with two columns (PL-gel MIXED-D $300 \times 7.5 \mathrm{~mm}$, beads diameter $5 \mu \mathrm{m}$; linear part $4 \times 10^{2}$ to $4 \times 10^{5} \mathrm{~g} / \mathrm{mol}$, from Polymer Laboratories, UK). The calibration curve was based on poly(methyl methacrylate) (PMMA) standards (Polymer Laboratories, UK). Samples were filtered on a $0.2 \mu \mathrm{m}$ PTFE filter before being analysed at $35^{\circ} \mathrm{C}$ in chloroform (HPLC grade) at a flow rate of $1 \mathrm{~mL} / \mathrm{min}$. Toluene was used as a flow rate marker.

The LA:GA ratio, as well as the polymer end group, were checked by ${ }^{1} \mathrm{H}$ nuclear magnetic resonance $\left({ }^{1} \mathrm{H}\right.$ NMR) measurements (Bruker Avance-300 MHz spectrometer, USA). These analyses were performed in 5-mm diameter tubes by dissolving around $20 \mathrm{mg}$ of PLGA in $1 \mathrm{~mL}$ of $\mathrm{CDCl}_{3}$. In order to identify the mobile protons, a second measurement was performed on the same sample after the addition of a drop of deuterium oxide. 


\subsection{NP preparation}

Bare PLGA NPs (called PLGA NPs) were prepared by nanoprecipitation, as described previously [35]. Briefly, $150 \mathrm{mg}$ of PLGA were dissolved in $15 \mathrm{~mL}$ of acetonitrile. This organic solution was then added dropwise into $45 \mathrm{~mL}$ of water under stirring, thanks to a syringe pump. After polymer nanoprecipitation, the organic solvent, as well as a part of the water, were removed by evaporation under vacuum, with a rotary evaporator. The process was stopped when $6 \mathrm{~mL}$ of suspension remained in the flask (NP concentration of $25 \mathrm{mg} / \mathrm{mL}$ ).

PLGA NPs covered with PVA (called PLGA-PVA NPs) were prepared by emulsion-evaporation, following a previously described protocol [36]. First, $100 \mathrm{mg}$ of PLGA were dissolved in $5 \mathrm{~mL}$ of a mixture of dichloromethane and acetone (50:50). This solution was pre-emulsified with $20 \mathrm{~mL}$ of an aqueous solution of PVA $0.25 \% \mathrm{w} / \mathrm{v}$ by vortex, and then emulsified with a sonication probe. The organic phase was evaporated by waiting $3 \mathrm{~h}$ at room temperature under stirring. The NP suspension was finally purified, using an ultracentrifuge (Beckman-Coulter, USA), $1 \mathrm{~h}$ at $27,440 \mathrm{~g}$ and $4^{\circ} \mathrm{C}$. The supernatant was removed and replaced by $4 \mathrm{~mL}$ of water (NP concentration of $25 \mathrm{mg} / \mathrm{mL}$ ). Preliminary results suggested that PLGA-PVA NPs had similar characteristics, whatever the PLGA type. Indeed, a previous publication of our group suggested that PVA governs the characteristics of PLGA-PVA NPs [6], so it was decided to prepare PLGAPVA NPs with only one PLGA type to reduce the number of studied systems. An ester-ending polymer (PLGA $753 \mathrm{~S}$ ) was chosen, as it is more hydrophobic, to emphasise the potential effect of the hydrophilic PVA coverage on the characteristics of NPs.

\subsection{NP characterisation}

\subsubsection{Size and $\zeta$-potential measurements}

The mean hydrodynamic diameter and $\zeta$-potential of NPs were measured by Dynamic Light Scattering (DLS), using a Zetasizer (Nano ZS, Malvern Instruments, France, $633 \mathrm{~nm} \mathrm{He-Ne}$ laser, Smoluchowski equation) operating at $25^{\circ} \mathrm{C}$ with a $173^{\circ}$ scattering angle. The NP suspension was diluted, until reaching an attenuator value of 6 , in MilliQ water or in a $1 \mathrm{mM}$ $\mathrm{NaCl}$ aqueous solution respectively for size distribution or zeta potential measurements. Each sample was analysed three times, to determine the $\zeta$-potential, the hydrodynamic diameter ("z-average", obtained by the cumulant fit analysis), and the Pdl reflecting the size distribution width. These three parameters were reported as an average value \pm standard deviation, calculated with the data of three different samples.

\subsubsection{Amount of PVA adsorbed on the surface of NPs}

The amount of PVA adsorbed at the PLGA-PVA NP surface after purification was indirectly measured by determining the PVA concentration in the supernatant after the centrifugation step of the emulsion-evaporation preparation process. This method, described in a previous publication [6], is based on the formation of a green-coloured complex between PVA and iodine in presence of boric acid. The supernatant was diluted with purified water so that PVA concentrations were within the range of the calibration curve ( 5 to $50 \mu \mathrm{g} / \mathrm{mL}$ of PVA). Then, 
$3 \mathrm{~mL}$ of a boric acid solution $(3.8 \% \mathrm{w} / \mathrm{v})$ and $0.6 \mathrm{~mL}$ of an iodine solution $(1.27 \% \mathrm{w} / \mathrm{v}$ of iodine and $2.5 \% \mathrm{w} / \mathrm{v}$ of potassium iodide) were added. The volume was adjusted to $10 \mathrm{~mL}$ with purified water. The absorbance of this solution was measured with a UV spectrophotometer (V530 UV/Vis spectrophotometer, Jasco, Japan), at $650 \mathrm{~nm}$ using the mixture of boric acid and aqueous iodine as a reference.

\subsubsection{Study of NP wettability}

NP wettability was assessed using contact angle measurements by sessile drop method on PLGA films and NP tablet. The film preparation was adapted from methods previously used by other teams to characterise PLGA wettability $[37,38]$. Glass slides were thoroughly cleaned with detergent and rinsed with purified water, and acetone. Then, a PLGA solution in dichloromethane was prepared with a concentration of $5 \mathrm{mg} / \mathrm{mL}$, and $25 \mu \mathrm{L}$ were deposited on a dry slide. This solution was left to dry $15 \mathrm{~min}$ at $18^{\circ} \mathrm{C}$, and then $24 \mathrm{~h}$ at $70^{\circ} \mathrm{C}$.

Besides, NP tablets were prepared from NP suspensions. First, NP suspensions of each type were frozen by immersion in liquid nitrogen and left in a freezer-drier Alpha 2-4 LD (Christ, Germany) for $24 \mathrm{~h}$. The condenser temperature was set at $-80^{\circ} \mathrm{C}$ and the pressure was lower than $1 \mathrm{mbar}$. Then, $20 \mathrm{mg}$ of freeze-dried NPs were deposited in a cylindrical compression die with a diameter of $0.7 \mathrm{~cm}$ (die of the Qwik Handi-Press Set, Thermo Electron Corporation, USA). A force of $400 \mathrm{~N}$ was applied on top of the compression die at a speed of $0.05 \mathrm{~mm} / \mathrm{s}$ and hold for $10 \mathrm{~s}$ using a TA.XTplus Texture Analyser (Stable Micro Systems, UK) to form a tablet.

The contact angle was measured with a drop shape analyser (Tracker, Teclis, France) in air at $18^{\circ} \mathrm{C}$, by drop shape analysis with the apparatus software (Windrop). A $5-\mu \mathrm{L}$ drop of water was gently deposited at the surface of the PLGA film or NP tablet. The value was taken $5 \mathrm{~s}$ after drop deposition, to let the drop reach its equilibrium shape. This equilibrium took place in a short period of time as there was no imbibition, neither on the films nor on the tablets. For each type of substrate, ten measurements were performed, on ten different films and tablets.

The significance of the differences observed between each type of NPs was tested statistically using the software Prism 5 (GraphPad Software, USA). For each type of NPs, the ten contact angle values were considered, as Grubbs tests indicated the absence of outliers. A D'Agostino-Pearson test was performed first to verify the normality of the distribution, for each set of ten values. Once the normality attested, a one-way ANOVA followed by Tukey's multiple comparison test was performed, to assess the significance of the differences between each set of data one by one.

\subsection{Emulsion preparation}

Emulsions ( $5 \mathrm{~g}$ ) with different water/oil ratios, from $95 / 5$ to $30 / 70$ were prepared. NP concentration in aqueous phase was set at $25 \mathrm{mg} / \mathrm{mL}$. Both NP suspension and Miglyol 812N were placed together in a vial and emulsified with a $5 \mathrm{G}$ dispersing tool, set on an Ultra-turrax (IKA T10 basic), at 20,000 rpm for $2 \mathrm{~min}$. Room temperature was set at $18^{\circ} \mathrm{C}$. 


\subsection{Emulsion characterisation}

\subsubsection{Macroscopic aspect}

The emulsion aspect has been observed after a period of storage of 7 days, at $18^{\circ} \mathrm{C}$ and protected from light.

\subsubsection{Confocal Laser Scanning Microscopy (CLSM)}

The microscopic structure of the emulsions was assessed for each type of NPs with CLSM, using an inverted microscope (TCS SP8-gated STED, Leica Microsystems, Germany) equipped with a WLL laser and a HC PL APO 40x/1.10 CORR CS2 water immersion objective lens. The emulsions were observed within the first hour following their preparation. Before collecting the samples, the emulsions were homogenised by inverting the tubes three times. Then the samples were placed in a curved glass slide with a cover glass slip on top. It prevented the deformation of emulsion droplets usually observed when using a flat glass slide. During NP preparation process, NPs were labelled in red by replacing $0.15 \mathrm{mg}$ of PLGA by a PLGA-rhodamine B conjugate. The aqueous phase was labelled in green with calcein $(0.08 \mathrm{mg} / \mathrm{mL})$. A 563-nm excitation wavelength was used, and bandwidth detection was set between 600 and $710 \mathrm{~nm}$ to collect the corresponding "red" fluorescence emission. A 488-nm excitation wavelength was used, and bandwidth detection was set between 500 and $535 \mathrm{~nm}$ to collect the corresponding "green" fluorescence emission. To avoid reflection, a hybrid detector under gated mode (0.3$6.5 \mathrm{~ns}$ ) was used. Green and red fluorescence emissions were collected under a sequential mode with the pinhole set at 1.0 Airy unit giving a $1.27 \mu \mathrm{m}$ optical slice thickness. Twelve-bit images were acquired with a definition of 1024 x 1024 pixels.

\subsubsection{Scanning Electron Cryo-Microscopy (CryoSEM)}

A sample of each emulsion was gently deposited in a gold-plated copper cupule with dome shaped indentation of $1.4 \mathrm{~mm}$ central diameter. Samples were then quickly frozen without any cryoprotectant by plunge in liquid ethane with a Leica CPC apparatus (Leica microsystems, Austria) without cryoprotectant. They were transferred to a Leica ACE 600 fracturing/coating apparatus, thanks to a Leica VCT 100 loading station and shuttle (Leica microsystems, Austria). They were freeze-fractured at $-150^{\circ} \mathrm{C}$ (high vacuum around $4 \times 10^{-6} \mathrm{mbar}$ ), with a blade or a scalpel and then coated by sputtering with $3 \mathrm{~nm}$ of Iridium (at $8 \times 10^{-3} \mathrm{mbar}$ and $80 \mathrm{~mA}$ upon Argon).

Finally, observations were performed at $-150^{\circ} \mathrm{C}$ in a Field Emission SEM Gemini 500 (Zeiss) operating at $790 \mathrm{~V}$ under high vacuum in the observation chamber, around $1 \times 10^{-6} \mathrm{mbar}$. The objective aperture diameter was set at $15 \mu \mathrm{m}$ and the working distance was between 2.2 and $2.8 \mathrm{~mm}$. Secondary electrons were collected with the in-lens detector. Images were acquired with a definition of $1024 \times 768$ pixels. Scan speed and line or drift compensation frame integrations were adjusted during observations. 


\subsubsection{Differential scanning calorimetry (DSC)}

DSC experiments were carried out using a Perkin-Elmer DSC Diamond apparatus equipped with an Intracooler 2P cooling device and connected to a Pyris Thermal Analysis Software System 9.1. The calorimeter was calibrated according to IUPAC recommendations, for both temperature and enthalpy [39]. The polymers, in the range of 2 to $6 \mathrm{mg}$, were accurately weighed and sealed within 50- $\mu \mathrm{L}$ aluminium pans (pan with holes, part BO143019 and cover, part BO143003); an empty pan was used as a reference. Samples were cooled from 55 to $-5^{\circ} \mathrm{C}$ at a constant rate, $|\mathrm{dT} / \mathrm{dt}|=5^{\circ} \mathrm{C} \cdot \mathrm{min}^{-1}$ and heated from -5 to $55^{\circ} \mathrm{C}$ at different rates, $\mathrm{dT} / \mathrm{dt}=5$, 10,15 and $20^{\circ} \mathrm{C} \cdot \mathrm{min}^{-1}$. The first scan was preceded by a 10 -min isotherm at $25^{\circ} \mathrm{C}$ to allow the samples to reach thermal equilibrium. All the transitions were found to be reversible and reproducible in the repeated scans. To eliminate the effects of the heating rate on the $T_{g}$, the value was extrapolated to zero rate by linear regression. This value, called $T_{g(0)}$, was the one we used to compare the samples.

To evaluate PLGA behaviour in presence of oil and water, emulsions were prepared with each type of NPs, following the usual procedure described earlier (see Section 2.5). The water/oil ratio was set at $90 / 10(\mathrm{w} / \mathrm{w})$. A sample of emulsion, in the range of 14 to $17 \mathrm{mg}$, were accurately weighed and hermetically sealed within 50- $\mu \mathrm{L}$ aluminium pans (pan part BO143017 and cover part BO143003); an empty pan was used as a reference. The cooling parameters were like those used for the polymer. Only one heating step was done, at a rate of $\mathrm{dT} / \mathrm{dt}=20^{\circ} \mathrm{C} \cdot \mathrm{min}^{-1}$. Indeed, performing analyses at smaller rates resulted in very weak signals. The scan was still preceded by a $10-\mathrm{min}$ isotherm at $25^{\circ} \mathrm{C}$. The extrapolation to obtain the $T_{g}$ at zero rate was done thanks to the linear regression obtained with the polymer.

\section{Results and discussion}

\subsection{Polymer and NP characterisation}

Prior to NP preparation, the various PLGA polymers used in this study were fully characterised in terms of chemical structure and molar mass (Table 1). ${ }^{1} \mathrm{H}$ NMR analysis confirmed that all the PLGA were composed of $75 \%$ of LA and $25 \%$ of GA, in good agreement with provider's specification (Supporting Material 1). The end group of PLGA $752 \mathrm{H}$ and PLGA $753 \mathrm{H}$ was a carboxylic acid, while PLGA 752 S and PLGA $753 \mathrm{~S}$ ended by an ester group (respectively containing 10 and 8 carbons). Concerning the mass-averaged molar masses $M_{w}$, determined by SEC relative to PMMA standards, they were twice higher for PLGA 753 than for PLGA 752 $\left(\mathrm{M}_{\mathrm{w}} \approx 32,000 \mathrm{~g} / \mathrm{mol}\right.$ for PLGA 753 versus $\mathrm{M}_{\mathrm{w}} \approx 14,000 \mathrm{~g} / \mathrm{mol}$ for PLGA 752).

PLGA NPs were then successfully prepared by a nanoprecipitation method in purified water. Their size distribution and $\zeta$-potential, studied by DLS, are reported in Table 1. PLGA molar mass seemed to have no or little influence on the NP size and $\zeta$-potential, in the range of molar masses studied. However, acid-ending PLGA $(752 \mathrm{H}$ and $753 \mathrm{H})$ led to a higher $\zeta$-potential in absolute value (around $-50 \mathrm{mV}$ ) compared to ester-ending PLGA (752 S and $753 \mathrm{~S}$, around $30 \mathrm{mV}$ ), because of the exposure of ionised acid end groups at the NP surface [40] (Supporting 
Material 2). Also, NPs prepared with an ester-ending polymer (752 S and $753 \mathrm{~S}$, around $220 \mathrm{~nm}$ ) were larger than those prepared with an acid-ending polymer $(752 \mathrm{H}$ and $753 \mathrm{H}$, around $160 \mathrm{~nm}$ ), as described in literature [41] (further discussed in Supporting Material 2). Thus, NP average size was mainly influenced by the PLGA ending, even if the size variation remained modest.

PLGA-PVA NPs were prepared with PLGA $753 \mathrm{~S}$ by the emulsion-evaporation method using PVA, a neutral polymer, as a stabilizer for the emulsification step. The resulting NPs had a size in the same range as NPs made by nanoprecipitation but differed in terms of $\zeta$-potential. The almost neutral $\zeta$-potential of the PLGA-PVA NPs can be explained by the presence of residual PVA chains anchored at the NP surface (estimated at $9 \mathrm{mg} / 100 \mathrm{mg}$ of PLGA), shielding the surface charges of PLGA $[6,40]$.

Table 1: Characteristics of PLGA (in chloroform by ${ }^{1} \mathrm{H}$ NMR and SEC), and NPs (by DLS). Size analysis was performed in purified water, and $\zeta$-potential in $\mathrm{NaCl} 1 \mathrm{mM}$.

\begin{tabular}{|c|c|c|c|c|c|c|}
\hline \multirow[b]{2}{*}{ Studied NPs } & \multicolumn{3}{|c|}{ Polymer characteristics } & \multicolumn{3}{|c|}{ NP characteristics } \\
\hline & LA/GA ratio & End group & $\mathrm{M}_{\mathrm{w}}(\mathrm{g} / \mathrm{mol})$ & $\begin{array}{l}\text { Hydrodynamic } \\
\text { diameter }(\mathrm{nm})\end{array}$ & Pdl & $\zeta$-potential $(\mathrm{mV})$ \\
\hline PLGA-PVA 753S & $75 / 25$ & ester $\mathrm{C} 10$ & 33,000 & $202 \pm 1$ & $0.07 \pm 0.03$ & $-4.1 \pm 0.4$ \\
\hline PLGA 752 H & $75 / 25$ & acid & 14,000 & $162 \pm 3$ & $0.08 \pm 0.01$ & $-53 \pm 3$ \\
\hline PLGA 753 H & $75 / 25$ & acid & 32,000 & $155 \pm 5$ & $0.07 \pm 0.01$ & $-52 \pm 3$ \\
\hline PLGA 753 S & $75 / 25$ & ester $\mathrm{C} 10$ & 33,000 & $213 \pm 18$ & $0.07 \pm 0.01$ & $-34 \pm 2$ \\
\hline PLGA 752 S & $75 / 25$ & ester C8 & 14,000 & $238 \pm 18$ & $0.07 \pm 0.02$ & $-26 \pm 3$ \\
\hline
\end{tabular}

To conclude, all the NPs produced had a narrow size distribution (Pdl $\approx 0.07$ ), and the PLGA influence on the average size was quite low, all the NPs exhibiting a size around $200 \mathrm{~nm}$ whatever their composition and preparation process. They mainly differed by their $\zeta$-potential, suggesting differences in their surface properties.

\subsection{PLGA characteristics influence the emulsion properties}

\subsubsection{Influence of NP wettability}

The surface properties of NPs have a major influence on their wettability, which impacts Pickering emulsion morphology and stability [42]. It is therefore essential, in order to understand the behaviour of NPs in the emulsions, to assess their wettability. Ideally, this latter must be evaluated by measuring the contact angle in the three-phase system [4]. However, this angle is difficult to measure, as it requires the use of highly sophisticated techniques. Thus, we decided to perform a common method, measuring the contact angle between a drop of water and a flat PLGA substrate, in air. This contact angle is not the three-phase contact angle, but it is a useful approximation to compare the different NPs. The first results were obtained on PLGA 
films (Table 2). All the contact angle values were comprised between 67 and $78^{\circ}$, which matches with results described in literature for various types of PLGA (usually around $75^{\circ}$, using dichloromethane as solvent) $[37,38,43]$. Still, it appears that PLGA characteristics influenced the contact angle. Two groups can be distinguished: films made of PLGA 753 S and 752 S showed a contact angle between 74 and $78^{\circ}$, whereas films composed of PLGA $753 \mathrm{H}$ and $752 \mathrm{H}$ were more hydrophilic with a contact angle of $67^{\circ}$. Statistic tests confirmed the significance of the difference between ester-ending and acid-ending polymers ( $p$-value $\leq 0.001$ ). This shows that the polymer end group had a major influence on NP wettability. This is in good agreement with the $\zeta$-potential values discussed previously, which confirms an exposure of the acid moieties at the NP surface. Also, a slight effect of the PLGA molar mass can be noticed: PLGA 752 S NPs were a little more hydrophobic than PLGA 753 S NPs ( $p$-value $\leq 0.001$ ). This minor effect could be due to a higher polymer chains content in PLGA 752 S NPs (low molar mass) than in PLGA 753 S NPs (high molar mass), for an equivalent mass. This results in a higher number of end groups at the NP surface for PLGA 752 S NPs than PLGA 753 S NPs, which would modulate the surface hydrophobicity. It should be noted that this phenomenon was not observed with acidending PLGA ( $p$-value > 0.05).

These first results obtained with PLGA films showed the possibility to discriminate the PLGA types based on their wettability by water. However, this substrate might not be the most suitable one. First, it is difficult to reproduce the PVA coverage on a film, with the same amount of PVA and the same organisation as on the PLGA-PVA NPs (NA in Table 2). Also, the drop of water deposited for the contact angle measurement could dissolve the PVA film, biasing the result. Besides, the PLGA conformation during a simple drying process (film/air interface) may be different from the polymer conformation during the nanoprecipitation process (NP/water interface). This could induce a difference in the surface structure between films and NPs, which might have some consequences on the contact angle. For these reasons, we prepared tablets composed of the NPs themselves, to be as representative as possible from the materials used in the emulsions. Contact angle measurements on particle tablets had already been proposed for other types of materials, such as clays [44], metal oxides [45], nitrocellulose [46], or silica [47]. The necessary compression force, though, was much lower in our case, as PLGA and PLGAPVA NPs are quite soft [6] and appeared to be cohesive.

The contact angles of each type of tablet with water in air are showed in Table 2. Globally, the results were comparable to the ones obtained on PLGA films: ester-ending PLGA (753 S and $752 \mathrm{~S})$ were more hydrophobic than NPs composed of acid-ending PLGA (753 H and $752 \mathrm{H}$ ), with a $p$-value lower than 0.001 . The molar mass also had a slight impact on the wettability of ester-ending PLGA NPs ( $p$-value $\leq 0.05)$. But the wettability measurements on NP tablets also provided new information. First, the range of contact angle values was broader when measured on tablets (from 82 to $109^{\circ}$, for bare PLGA NP) compared to the films (from 67 to $78^{\circ}$ ). This confirmed the assumption of a different polymer conformation at the film surface compared to the NP surface. As it was made of NPs, the surface of tablets appeared to be more representative of the real NP surface than the surface of model films. It should be noted that the roughness of the tablet surface (ranging between 37 and $121 \mathrm{~nm}$, as determined from AFM measurements) was very low, so it likely had no influence on the contact angle (Supporting Material 3). Thus, contact angles measurements on NP tablets should be favoured, as it reflects 
the wettability of the PLGA NPs by water in the conditions of its use in emulsions. Also, this method allowed us to confirm the influence of the PVA coverage of the NPs, which could not be done with films. The high contact angle of hydrophobic PLGA 753 S NPs $\left(\theta=102^{\circ}\right)$ was dramatically decreased when PVA, a hydrophilic polymer, was adsorbed at the surface, making NP surface far more hydrophilic $\left(\theta=40^{\circ}\right)$. This means that the coverage of the PLGA NP surface by PVA masked PLGA influence, as suggested by the $\zeta$-potential values.

Table 2: NP surface wettability, represented by (i) the contact angle between a drop of water and different PLGA substrates (PLGA films or NP tablets) after $5 \mathrm{~s}$ of contact, and (ii) the oil amount necessary to obtain phase inversion from $\mathrm{O} / \mathrm{W}$ to W/O for emulsions prepared with each type of NPs

\begin{tabular}{|c|c|c|c|}
\hline NP studied & $\begin{array}{l}\text { Contact angle wi } \\
\text { On PLGA films }\end{array}$ & $\begin{array}{l}\text { water, in air }\left(^{\circ}\right) \\
\text { On NP tablets }\end{array}$ & $\begin{array}{l}\text { Oil\% for phase } \\
\text { inversion (w/w) }\end{array}$ \\
\hline PLGA-PVA 753S & NA & $39 \pm 7$ & $60-70 \%$ \\
\hline PLGA 752 H & $67 \pm 3$ & $82 \pm 6$ & $30-35 \%$ \\
\hline PLGA 753 H & $67 \pm 2$ & $88 \pm 5$ & $20-25 \%$ \\
\hline PLGA 753 S & $74 \pm 3$ & $102 \pm 6$ & $15-20 \%$ \\
\hline PLGA 752 S & $78 \pm 2$ & $109 \pm 4$ & $5-10 \%$ \\
\hline
\end{tabular}

NA: Not Applicable

After studying the wettability of the different types of NPs, emulsions were prepared to analyse the NP influence on the emulsion behaviour. For all types of NPs, several emulsions were prepared with increasing amounts of oil, until reaching the catastrophic phase inversion from O/W emulsions to W/O emulsions [48] (Supporting Material 4). The oil amount added to obtain this inversion is reported in Table 2. Interestingly, the more hydrophilic the NPs, the more oil was necessary to reach the catastrophic phase inversion. This behaviour perfectly matched with Finkle's rule: hydrophilic NPs preferably stabilised O/W emulsions, and conversely for hydrophobic NPs [49,50]. As this is in line with the contact angle values, it consolidated the relevance of the contact angle measurement method on tablets.

To illustrate more precisely the difference of emulsion behaviour, emulsions were prepared with the five different types of NPs, in the same conditions, at a fixed water/oil ratio of 90/10 (w/w). On CLSM images, one can clearly visualise red-labelled NPs adsorbed at the interfaces between water and oil, for all types of NPs, as expected for Pickering emulsions (Figure 1). Interestingly, a gradual variation of the emulsion structure as a function of NP wettability could be observed. At this water/oil ratio, very hydrophilic NPs (covered by PVA) stabilised a simple O/W emulsion (Figure 1a). In the same conditions, hydrophobic PLGA 752 S NPs stabilised a simple W/O emulsion (Figure 1e), even if the oil amount was very low (10\%). This is a spectacular effect of the hydrophobicity of these NPs. Moreover, this image suggests the formation of a network of PLGA 752 SNPs, stabilising the water droplets. The three other types of NPs with intermediate wettability (PLGA 752 H NPs, PLGA 753 H NPs and PLGA 753 S NPs, 
respectively Figure $1 \mathrm{~b}-\mathrm{d}$ ) stabilised multiple $\mathrm{W} / \mathrm{O} / \mathrm{W}$ emulsions. It is interesting to notice the formation of both W/O and O/W interfaces by a single-step process, when multiple emulsions are usually prepared in two steps, with classical surfactants [51] as well as with solid particles [52]. This has already been described with PLGA NPs, in a previous study by our group [6]. We assume this behaviour might be due to the contribution of a set of favourable conditions, such as: (i) a sufficient oil amount to promote coalescence during the process, which induced the inclusion of continuous phase in the oil droplets [53,54]; (ii) an excess of NPs, that were available to stabilise the surface of inner droplets [54]; (iii) an intermediate wettability of all [28] or part of the NPs [55] in the three-phase system, which allowed them to stabilise both water-inoil and oil-in-water interfaces; and finally (iv) a short emulsification time, not sufficient to reach the potential phase inversion usually following the formation of multiple emulsion [56] (Supporting Material 4). The preparation of multiple Pickering emulsions in one step has already been described in literature, even if their obtention is more common when NPs are presuspended in the oil phase [57].
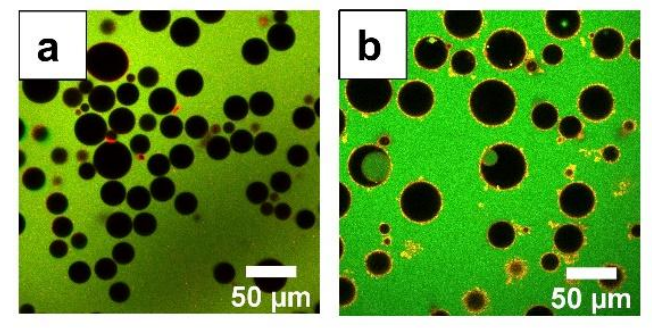

PLGA-PVA NPS

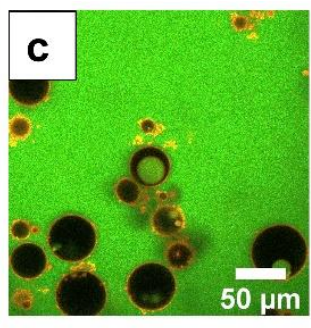

PLGA 753 H NPs

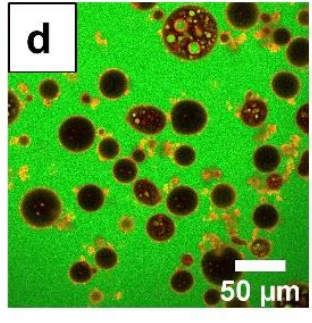

PLGA 753 S NPs
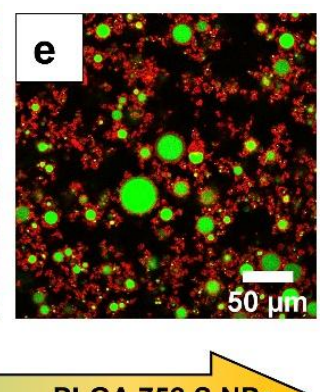

Hydrophilic NP

Hydrophobic NP

Figure 1: CLSM images of emulsions with a water/oil ratio of $90 / 10(\mathrm{w} / \mathrm{w})$, prepared few minutes before the observation, and stabilised by: a) PLGA-PVA 753 S NPs, b) PLGA 752 H NPs, c) PLGA 753 H NPs,

d) PLGA 753 S NPs, e) PLGA 752 S NPs. The NPs are red-labelled by PLGA-rhodamine, while the water is green-labelled by calcein.

NP wettability had also some consequences on the macroscopic aspect of the emulsions. Some macroscopic pictures of the five emulsions microscopically studied previously were taken after seven days of storage (Figure 2). All these emulsions were quite fluid, allowing droplets to form a cream layer, topping the excess of water phase. First, variation of the cream thickness could be observed: PVA-covered NPs (Figure 2a) led to a thin cream layer (20\% of the total height of the emulsion), whereas PLGA 752 H NPs, PLGA 753 H NPs and PLGA 753 S NPs (Figure 2b-d) stabilised a very thick cream layer (50\% of the total height of the emulsion). This thick layer is the macroscopic consequence of the presence of multiple droplets, as observed with CLSM (Figure 1). The thickness of the cream stabilised by PLGA 752 S NPs could not be assessed precisely, due to its very unusual aspect (Figure 2e), discussed in the next section. Macroscopic observations also provided information about the affinity of NPs for the interphase. For the emulsions stabilised by PLGA-PVA 753 S NPs, PLGA 752 H NPs, and PLGA 753 H NPs (Figure 
$2 a-c)$, the aqueous phase was almost as cloudy as the initial NP suspension before emulsification. This was due to the excess of NPs that remained in the water phase after emulsification, since these NPs were hydrophilic. For the two other emulsions, stabilised by hydrophobic PLGA 753 S NPs, and PLGA 752 S NPs (Figure 2d-e), the aqueous phase was logically transparent, as NPs did not have a great affinity for water. Finally, the stability of the emulsions could be evaluated. Indeed, the Figure 2 a showed a beginning of coalescence at the top of the cream, while the other emulsions were stable (Supporting Material 5). This can be attributed to the high hydrophilicity of the PVA-covered NPs, favouring their presence in the aqueous phase rather than at the oil/water interface $[28,31,34]$.

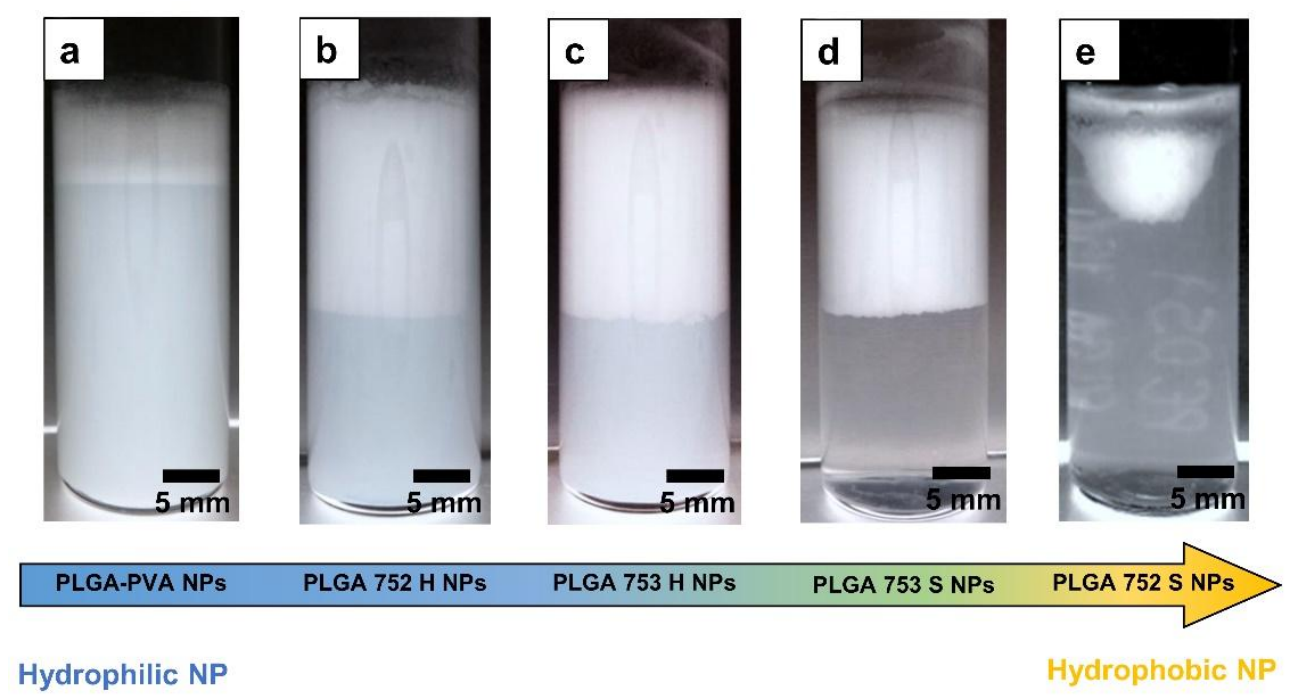

Figure 2: Macroscopic aspect of emulsions at day 7 prepared with a water/oil ratio of $90 / 10(\mathrm{w} / \mathrm{w})$ and stabilised by: a) PLGA-PVA 753 S NPs, b) PLGA 752 H NPs, c) PLGA 753 H NPs, d) PLGA 753 S NPs, e) PLGA 752 S NPs

\subsubsection{Influence of the glass transition}

Besides wettability, the second key parameter studied to understand the behaviour of the emulsions was the $T_{g(0)}$ of PLGA. Its graphical determination is explained in Supporting Information 6. As shown in Table 3, the ester-ending polymers had lower $\mathrm{T}_{\mathrm{g}(0)}$ than the acidending ones. It has been well described that $T_{g(0)}$ decreases when the mobility of the polymer chains increases. Yet, Flory and Fox showed that end chain units exhibited excess of free volume compared to units within the chain [58], so it is more likely to influence the polymer mobility. Thus, modifying the end group induce a modification of the $T_{g(0)}$ of the polymer. One can assume that the presence of ionized carboxyl end groups generates electrostatic interactions that forces the organisation of the polymer chains, reducing their mobility. Ester end groups do not display charges, hence a better mobility, and a lower $\mathrm{T}_{g(0)}$. Besides, as expected, a shorter chain induced a lower $\mathrm{T}_{\mathrm{g}(0)}: 44.5^{\circ} \mathrm{C}$ and $34.3^{\circ} \mathrm{C}$ for the PLGA $752 \mathrm{H}$ and S respectively, 
versus $47.7^{\circ} \mathrm{C}$ and $45.1^{\circ} \mathrm{C}$ for the PLGA $753 \mathrm{H}$ and S. Indeed, as explained in Section 3.2.1, for a given mass, the shorter the chains, the more numerous are the end groups and hence the lower is $T_{g(0)}[58,59]$. This is consistent with observations made by other groups on PLGA [60]. These trends, observed on the polymers, were confirmed by the results in the emulsions. Nevertheless, when NPs were in contact with oily and aqueous phases, the $T_{g(0)}$ of the polymer decreased dramatically, compared to the dry polymer. The liquid phases acted as plasticisers, by penetrating NP structure and creating some additional free volume [61]. Some results obtained on NP suspensions tend to prove that water was the main plasticiser, oil having a minor effect on the $T_{g(0)}$ values (data not shown). Some other studies also highlighted the decrease of $T_{g(0)}$ of PLGA in presence of water [62,63]. Finally, PVA-covered PLGA 753 S NPs exhibited a slightly higher $\mathrm{T}_{g(0)}\left(39.7^{\circ} \mathrm{C}\right)$ compared to the bare ones $\left(37.2^{\circ} \mathrm{C}\right)$. This is in good agreement with the results of Bouissou et al. [64], but remains unexplained.

Table 3: $T_{g(0)}$ of dry PLGA and, $T_{g(0)}$ of PLGA NPs in the emulsions with a water/oil ratio of $90 / 10(w / w)$, obtained by DSC

\begin{tabular}{c||cc}
\hline NP studied & $\begin{array}{c}\mathrm{T}_{\mathrm{g}(0)} \text { of } \\
\text { PLGA polymer }\left({ }^{\circ} \mathrm{C}\right)\end{array}$ & $\begin{array}{c}\mathrm{T}_{\mathrm{g}(0)} \text { of NPs in } \\
\text { emulsions }\left({ }^{\circ} \mathrm{C}\right)\end{array}$ \\
\hline PLGA-PVA 753S & $45.1 \pm 0.3$ & $39.7 \pm 0.6$ \\
\hline PLGA 752 H & $44.5 \pm 0.2$ & $32.7 \pm 0.2$ \\
PLGA 753 H & $47.7 \pm 0.2$ & $37.6 \pm 0.2$ \\
\hline PLGA 753 S & $45.1 \pm 0.3$ & $37.2 \pm 0.4$ \\
PLGA 752 S & $34.3 \pm 0.6$ & $24.8 \pm 0.6$ \\
\hline
\end{tabular}

The $\mathrm{T}_{\mathrm{g}(0)}$ value of PLGA $752 \mathrm{~S}$ in the emulsion $\left(24.8^{\circ} \mathrm{C}\right)$ particularly attracted our attention. Indeed, it was very close to the room temperature, which could influence the behaviour of NPs during the emulsification process. This will be further discussed in the next paragraph, as cryoSEM observations allowed us to understand the mechanism of stabilisation of the emulsions.

CryoSEM images showed the microscopic structure of all the emulsions described above (Figure 3). The Figure 3a-d and corresponding cropped images showed NPs adsorbed at the interface between oil and water interface, as previously observed in CLSM images (Figure 1). PVA-covered NPs stabilised a simple O/W emulsion by forming a loosely packed monolayer (Figure $3 \mathrm{a}$ and corresponding cropped image). The wide space between the NPs could be explained by the PVA-coverage, generating steric hindrance between particles at the interface. It could also be explained by the high hydrophilicity of the PVA-covered NPs, not favouring their presence at the oil/water interface, hence a poor coverage. This might be the reason of the relative instability of this emulsion (Supplementary Information 5). For PLGA $753 \mathrm{H}$, PLGA $753 \mathrm{~S}$ and PLGA 752 H NPs, the particles were still visible, and formed an irregular layer, surrounded by flocs (Figure 3b-d and corresponding cropped images). If flocs have already been described with fumed silica [54], in our case the $\zeta$-potential of NPs (higher than $-30 \mathrm{mV}$, Table 1) should prevent aggregation. Also, these flocs were not present in the initial NP suspension, as shown 
by the particle size analysis (Table 1). Their formation, only happening close to the oil-water interface, remains unexplained. Besides, these three emulsions also presented some inner droplets of water, in good agreement with the CLSM images showing W/O/W emulsions. These inner droplets were covered by NP monolayers as well, ensuring their stability and preventing them from escaping from the oil droplets [54] (Supporting Material 4). Finally, the image of the emulsion stabilised by PLGA 752 S NPs (Figure 3e) surprisingly showed no NP at the interface. Instead of spherical NPs, undefined and irregular structures were observed. Our hypothesis is that, performing the emulsification at $18^{\circ} \mathrm{C}$ with a high shear rate during $2 \mathrm{~min}$, the temperature locally increased until exceeding the $T_{g(0)}$ value of PLGA $752 \mathrm{~S}\left(T_{g(0)}=24.8^{\circ} \mathrm{C}\right)$. The rubbery state of NPs allowed them to unfold under shear, and agglomerate. This would result in the formation of a network of NP debris. This theory is in supported by the presence of an irregular network in the oil phase observed on CLSM image (Figure 1e). This led to a material that could still be considered as a Pickering emulsion, but with a very unusual aspect and texture (Figure $2 e)$. So, the PLGA end group and molar mass would have an indirect influence on the emulsion morphology, by influencing the $T_{g}$ of PLGA. 


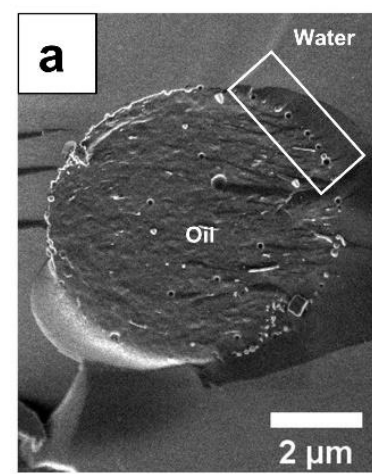

PLGA-PVA NPs

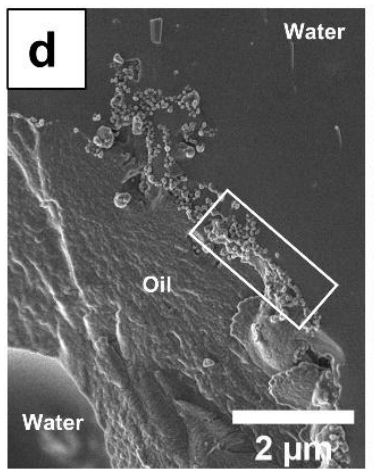

PLGA 752 H NPs

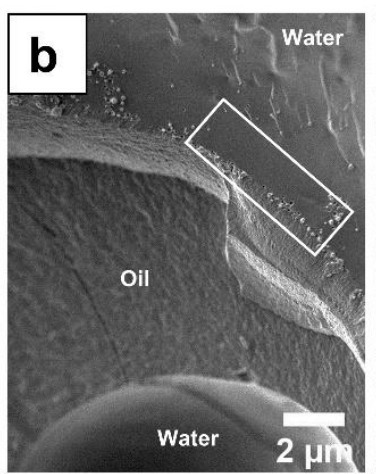

PLGA 753 H NPs

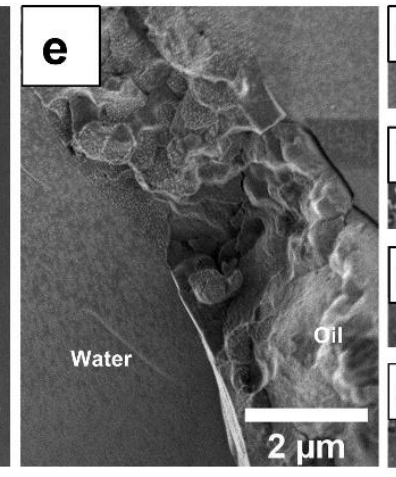

PLGA 752 S NPS

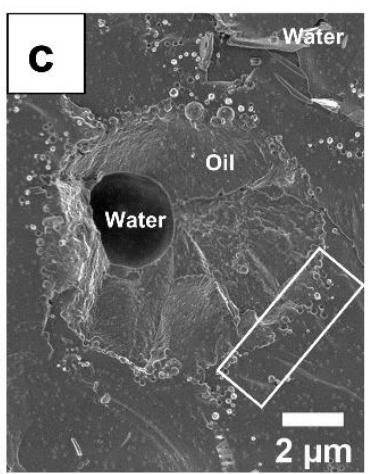

PLGA 753 S NPs

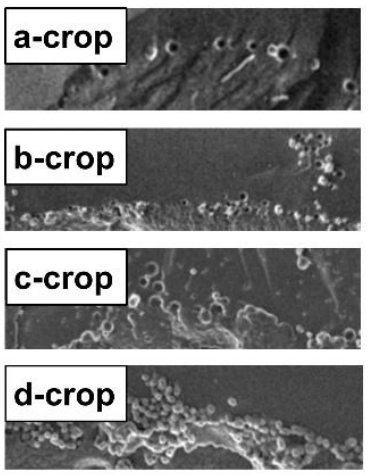

d-crop

Figure 3: CryoSEM images of frozen-fixed emulsions prepared with a water/oil ratio of 90/10 (w/w), prepared a few minutes before the observation, and stabilised by: a) PLGA-PVA 753 S NPs,

b) PLGA 753 H NPs, c) PLGA 753 S NPs, d) PLGA 752 H NPs, e) PLGA 752 S NPs.

Lower right cropped images show the NP organisation in the outlined regions.

\section{Conclusion}

This study demonstrated that the physico-chemical properties of PLGA constituting NPs, and hence NPs properties, were of the utmost importance to control the structure of the final Pickering emulsions. The molar mass and the end group of the PLGA directly affected the NP wettability and glass transition temperature. Indeed, ester-ending polymers provided a higher hydrophobicity and a lower $\mathrm{T}_{\mathrm{g}}$, compared to acid-ending polymers. Also, a smaller molar mass could also slightly exacerbate the effect of the end groups, as the number of these latter increase. NPs of various wettability were produced and used to stabilise different types of emulsions in accordance with Finkle's rule. However, producing NPs in presence of a stabilising polymer (such as PVA) masked the effect of the PLGA characteristics, as PVA-coverage drove the emulsion stabilisation. Finally, an unusual solid emulsion, stabilised by a network of NP debris, was described. The low $T_{g}$ value of the concerned PLGA was in cause, allowing the formation of the solid network during the emulsification, and leading to this unusual structure. 
To conclude, by changing the initial characteristics of the polymer, we could tune NP characteristics and hence the emulsion structure $(\mathrm{O} / \mathrm{W}, \mathrm{W} / \mathrm{O}$, multiple emulsions) and texture (fluid or solid emulsions). This is particularly attractive for drug delivery purposes, as a versatile formulation platform enabling the encapsulation of both hydrophilic and hydrophobic active substances.

\section{Acknowledgements}

N. Huang acknowledges the Agence Nationale de la Recherche (ANR) for its support through a Young Researchers grant (ANR-16-CE09-0003).

\section{References}

[1] B.P. Binks, Particles as surfactants-similarities and differences, Curr. Opin. Colloid Interface Sci. 7 (2002) 21-41. https://doi.org/10.1016/S1359-0294(02)00008-0.

[2] J. Xiao, Y. Li, Q. Huang, Recent advances on food-grade particles stabilized Pickering emulsions: Fabrication, characterization and research trends, Trends Food Sci. Technol. 55 (2016) 48-60. https://doi.org/10.1016/j.tifs.2016.05.010.

[3] J. Frelichowska, M.-A. Bolzinger, Y. Chevalier, Pickering emulsions with bare silica, Colloids Surf. Physicochem. Eng. Asp. 343 (2009) 70-74. https://doi.org/10.1016/j.colsurfa.2009.01.031.

[4] C. Albert, M. Beladjine, N. Tsapis, E. Fattal, F. Agnely, N. Huang, Pickering emulsions: Preparation processes, key parameters governing their properties and potential for pharmaceutical applications, J. Controlled Release. 309 (2019) 302-332. https://doi.org/10.1016/j.jconrel.2019.07.003.

[5] N. Branco, I. Lee, H. Zhai, H.I. Maibach, Long-term repetitive sodium lauryl sulfate-induced irritation of the skin: an in vivo study, Contact Dermatitis. 53 (2005) 278-284. https://doi.org/10.1111/j.0105-1873.2005.00703.x.

[6] C. Albert, N. Huang, N. Tsapis, S. Geiger, V. Rosilio, G. Mekhloufi, D. Chapron, B. Robin, M. Beladjine, V. Nicolas, E. Fattal, F. Agnely, Bare and Sterically Stabilized PLGA Nanoparticles for the Stabilization of Pickering Emulsions, Langmuir. 34 (2018) 1393513945. https://doi.org/10.1021/acs.langmuir.8b02558.

[7] H.K. Makadia, S.J. Siegel, Poly Lactic-co-Glycolic Acid (PLGA) as Biodegradable Controlled Drug Delivery Carrier, Polymers. 3 (2011) 1377-1397. https://doi.org/10.3390/polym3031377.

[8] C.E. Astete, C.M. Sabliov, Synthesis and characterization of PLGA nanoparticles, J. $\begin{array}{llllll}\text { Biomater. Sci. } & \text { Polym. } & \text { Ed. } & 17 & \text { (2006) }\end{array}$ https://doi.org/10.1163/156856206775997322.

[9] F.Y. Han, K.J. Thurecht, A.K. Whittaker, M.T. Smith, Bioerodable PLGA-Based Microparticles for Producing Sustained-Release Drug Formulations and Strategies for $\begin{array}{llllll}\text { Improving Drug Loading, } & \text { Front. } & \text { Pharmacol. } & 7 & \text { (2016). }\end{array}$ https://doi.org/10.3389/fphar.2016.00185. 
[10] I. Bala, S. Hariharan, M.R. Kumar, PLGA Nanoparticles in Drug Delivery: The State of the Art;, Crit. Rev. Ther. Drug Carrier Syst. 21 (2004) 387-422. https://doi.org/10.1615/CritRevTherDrugCarrierSyst.v21.i5.20.

[11] R.E. Eliaz, J. Kost, Characterization of a polymeric PLGA-injectable implant delivery system for the controlled release of proteins, J. Biomed. Mater. Res. 50 (2000) 388-396. https://doi.org/10.1002/(SICI)1097-4636(20000605)50:3<388::AID-JBM13>3.0.CO;2-F.

[12] N.H. Shah, A.S. Railkar, F.C. Chen, R. Tarantino, S. Kumar, M. Murjani, D. Palmer, M.H. Infeld, A.W. Malick, A biodegradable injectable implant for delivering micro and macromolecules using poly (lactic-co-glycolic) acid (PLGA) copolymers, J. Controlled Release. 27 (1993) 139-147. https://doi.org/10.1016/0168-3659(93)90217-S.

[13] P. Gentile, V. Chiono, I. Carmagnola, P. Hatton, An Overview of Poly(lactic-co-glycolic) Acid (PLGA)-Based Biomaterials for Bone Tissue Engineering, Int. J. Mol. Sci. 15 (2014) 3640-3659. https://doi.org/10.3390/ijms15033640.

[14] W. Jiang, R. Gupta, M. Deshpande, S. Schwendeman, Biodegradable poly(lactic-coglycolic acid) microparticles for injectable delivery of vaccine antigens, Adv. Drug Deliv. Rev. 57 (2005) 391-410. https://doi.org/10.1016/j.addr.2004.09.003.

[15] F. Danhier, E. Ansorena, J.M. Silva, R. Coco, A. Le Breton, V. Préat, PLGA-based nanoparticles: An overview of biomedical applications, J. Controlled Release. 161 (2012) 505-522. https://doi.org/10.1016/j.jconrel.2012.01.043.

[16] A. Taluja, Y.S. Youn, Y.H. Bae, Novel approaches in microparticulate PLGA delivery systems encapsulating proteins, J. Mater. Chem. 17 (2007) 4002. https://doi.org/10.1039/b706939a.

[17] Z. Xu, D. Wang, Y. Cheng, M. Yang, L.-P. Wu, Polyester based nanovehicles for siRNA delivery, Mater. Sci. Eng. C. 92 (2018) 1006-1015. https://doi.org/10.1016/j.msec.2018.05.031.

[18] J.-M. Lü, X. Wang, C. Marin-Muller, H. Wang, P.H. Lin, Q. Yao, C. Chen, Current advances in research and clinical applications of PLGA-based nanotechnology, Expert Rev. Mol. Diagn. 9 (2009) 325-341. https://doi.org/10.1586/erm.09.15.

[19] S. Fredenberg, M. Wahlgren, M. Reslow, A. Axelsson, The mechanisms of drug release in poly(lactic-co-glycolic acid)-based drug delivery systems-A review, Int. J. Pharm. 415 (2011) 34-52. https://doi.org/10.1016/j.jpharm.2011.05.049.

[20] A. Pandey, D.S. Jain, Poly Lactic-Co-Glycolic Acid (PLGA) Copolymer and Its Pharmaceutical Application, in: V.K. Thakur, M.K. Thakur (Eds.), Handb. Polym. Pharm. Technol., John Wiley \& Sons, Inc., Hoboken, NJ, USA, 2015: pp. 151-172. https://doi.org/10.1002/9781119041412.ch6.

[21] Y. Xu, C.-S. Kim, D.M. Saylor, D. Koo, Polymer degradation and drug delivery in PLGAbased drug-polymer applications: A review of experiments and theories, J. Biomed. Mater. Res. B Appl. Biomater. 105 (2017) 1692-1716. https://doi.org/10.1002/jbm.b.33648.

[22] D.K. Gilding, A.M. Reed, Biodegradable polymers for use in surgerypolyglycolic/poly(actic acid) homo- and copolymers: 1, Polymer. 20 (1979) 1459-1464. https://doi.org/10.1016/0032-3861(79)90009-0.

[23] R.A. Jain, The manufacturing techniques of various drug loaded biodegradable poly(lactide-co-glycolide) (PLGA) devices, Biomaterials. 21 (2000) 2475-2490. https://doi.org/10.1016/S0142-9612(00)00115-0. 
[24] X.S. Wu, N. Wang, Synthesis, characterization, biodegradation, and drug delivery application of biodegradable lactic/glycolic acid polymers. Part II: Biodegradation, J. Biomater. Sci. Polym. Ed. 12 (2001) 21-34. https://doi.org/10.1163/156856201744425.

[25] Z. Wang, Y. Wang, Tuning Amphiphilicity of Particles for Controllable Pickering Emulsion, Materials. 9 (2016) 903. https://doi.org/10.3390/ma9110903.

[26] Y. Meng, W. Sun, H. Yang, W. Wang, N. Jin, Y. Zhao, X. Zhang, H. Lü, Fine tuning of surface properties of $\mathrm{SiO} 2$ nanoparticles for the regulation of Pickering emulsions, Colloids $\begin{array}{llllll}\text { Surf. } & \text { Physicochem. } & \text { Eng. } & \text { Asp. } & 592 & \text { (2020) }\end{array}$ https://doi.org/10.1016/j.colsurfa.2020.124603.

[27] B.P. Binks, S.O. Lumsdon, Influence of Particle Wettability on the Type and Stability of $\begin{array}{lllll}\text { Surfactant-Free Emulsions, } & \text { Langmuir. } & 16 & \text { (2000) 8622-8631. }\end{array}$ https://doi.org/10.1021/la000189s.

[28] B.P. Binks, P.D.I. Fletcher, B.L. Holt, P. Beaussoubre, K. Wong, Phase inversion of particle-stabilised perfume oil-water emulsions: experiment and theory, Phys. Chem. Chem. Phys. 12 (2010) 11954. https://doi.org/10.1039/c0cp00558d.

[29] N. Yan, M.R. Gray, J.H. Masliyah, On water-in-oil emulsions stabilized by fine solids, Colloids Surf. Physicochem. Eng. Asp. 193 (2001) 97-107. https://doi.org/10.1016/S09277757(01)00748-8.

[30] E. Santini, E. Guzmán, M. Ferrari, L. Liggieri, Emulsions stabilized by the interaction of silica nanoparticles and palmitic acid at the water-hexane interface, Colloids Surf. $\begin{array}{lllll}\text { Physicochem. } & \text { Eng. } & \text { Asp. } & 460 & \text { (2014) 333-341. }\end{array}$ https://doi.org/10.1016/j.colsurfa.2014.02.054.

[31] W. Li, L. Yu, G. Liu, J. Tan, S. Liu, D. Sun, Oil-in-water emulsions stabilized by Laponite particles modified with short-chain aliphatic amines, Colloids Surf. Physicochem. Eng. Asp. 400 (2012) 44-51. https://doi.org/10.1016/j.colsurfa.2012.02.044.

[32] H. Lim, M. Jo, C. Ban, Y.J. Choi, Interfacial and colloidal characterization of oil-in-water emulsions stabilized by interface-tunable solid lipid nanoparticles, Food Chem. 306 (2020) 125619. https://doi.org/10.1016/j.foodchem.2019.125619.

[33] K.S. Silmore, C. Gupta, N.R. Washburn, Tunable Pickering emulsions with polymer-grafted lignin nanoparticles (PGLNs), J. Colloid Interface Sci. 466 (2016) 91-100. https://doi.org/10.1016/j.jcis.2015.11.042.

[34] F. Qi, J. Wu, G. Sun, F. Nan, T. Ngai, G. Ma, Systematic studies of Pickering emulsions stabilized by uniform-sized PLGA particles: preparation and stabilization mechanism, J. Mater. Chem. B. 2 (2014) 7605-7611. https://doi.org/10.1039/C4TB01165A.

[35] N. Grabowski, H. Hillaireau, J. Vergnaud, N. Tsapis, M. Pallardy, S. Kerdine-Römer, E. Fattal, Surface coating mediates the toxicity of polymeric nanoparticles towards human-like $\begin{array}{llllll}\text { macrophages, Int. } & \text { J. } & \text { Pharm. } & 482 & \text { (2015) }\end{array}$ https://doi.org/10.1016/j.jpharm.2014.11.042.

[36] S. Mura, H. Hillaireau, J. Nicolas, B. Le Droumaguet, C. Gueutin, S. Zanna, N. Tsapis, E. Fattal, Influence of surface charge on the potential toxicity of PLGA nanoparticles towards Calu-3 cells, Int. J. Nanomedicine. 6 (2011) 2591-2605. https://doi.org/10.2147//JN.S24552.

[37] C.P. Whitby, L.H. Lim, N. Ghouchi Eskandar, S. Simovic, C.A. Prestidge, Poly(lactic-coglycolic acid) as a particulate emulsifier, J. Colloid Interface Sci. 375 (2012) 142-147. https://doi.org/10.1016/j.jcis.2012.02.058. 
[38] T.I. Croll, A.J. O'Connor, G.W. Stevens, J.J. Cooper-White, Controllable Surface Modification of Poly(lactic-co-glycolic acid) (PLGA) by Hydrolysis or Aminolysis I: Physical, Chemical, and Theoretical Aspects, Biomacromolecules. 5 (2004) 463-473. https://doi.org/10.1021/bm0343040.

[39] G. Della Gatta, M.J. Richardson, S.M. Sarge, S. Stølen, Standards, calibration, and guidelines in microcalorimetry. Part 2. Calibration standards for differential scanning calorimetry (IUPAC Technical Report), Pure Appl. Chem. 78 (2006) 1455-1476. https://doi.org/10.1351/pac200678071455.

[40] S.K. Sahoo, J. Panyam, S. Prabha, V. Labhasetwar, Residual polyvinyl alcohol associated with poly (d,I-lactide-co-glycolide) nanoparticles affects their physical properties and cellular uptake, J. Controlled Release. 82 (2002) 105-114. https://doi.org/10.1016/S01683659(02)00127-X.

[41] A. Reisch, A. Runser, Y. Arntz, Y. Mély, A.S. Klymchenko, Charge-Controlled Nanoprecipitation as a Modular Approach to Ultrasmall Polymer Nanocarriers: Making Bright and Stable Nanoparticles, ACS Nano. 9 (2015) 5104-5116. https://doi.org/10.1021/acsnano.5b00214.

[42] B.P. Binks, J.A. Rodrigues, Types of Phase Inversion of Silica Particle Stabilized Emulsions

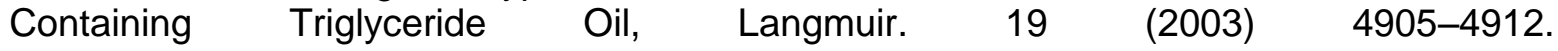
https://doi.org/10.1021/la020960u.

[43] É. Kiss, E.I. Vargha-Butler, Novel method to characterize the hydrolytic decomposition of biopolymer surfaces, Colloids Surf. B Biointerfaces. 15 (1999) 181-193. https://doi.org/10.1016/S0927-7757(99)00009-6.

[44] C. Jouany, P. Chassin, Determination of the surface energy of clay-organic complexes by contact angle measurements, Colloids Surf. 27 (1987) 289-303. https://doi.org/10.1016/0166-6622(87)80152-X.

[45] H. Elmotasem, H.K. Farag, A.A.A. Salama, In vitro and in vivo evaluation of an oral sustained release hepatoprotective caffeine loaded w/o Pickering emulsion formula Containing wheat germ oil and stabilized by magnesium oxide nanoparticles, Int. J. Pharm. 547 (2018) 83-96. https://doi.org/10.1016/j.jpharm.2018.05.038.

[46] H. Grau, A.Y. Fadeev, "Raincoat for explosives": Surface chemistry approach to control wetting of nitrocellulose with nitroglycerin, J. Colloid Interface Sci. 547 (2019) 145-152. https://doi.org/10.1016/j.jcis.2019.03.063.

[47] R. Pichot, Stability and characterisation of emulsions in the presence of colloidal particles and surfactants., d_ph, University of Birmingham, 2012. https://etheses.bham.ac.uk/id/eprint/3271/ (accessed April 11, 2020).

[48] B.P. Binks, S.O. Lumsdon, Catastrophic Phase Inversion of Water-in-Oil Emulsions Stabilized by Hydrophobic Silica, Langmuir. $16 \quad$ (2000) 2539-2547. https://doi.org/10.1021/la991081j.

[49] P. Finkle, H.D. Draper, J.H. Hildebrand, The theory of emulsification, J. Am. Chem. Soc. 45 (1923) 2780-2788. https://doi.org/10.1021/ja01665a002.

[50] V. Paunov, O. Cayre, P. Noble, S. Stoyanov, K. Velikov, M. Golding, Emulsions stabilised by food colloid particles: Role of particle adsorption and wettability at the liquid interface, J. Colloid Interface Sci. 312 (2007) 381-389. https://doi.org/10.1016/j.jcis.2007.03.031. 
[51] B.F.B. Silva, C. Rodríguez-Abreu, N. Vilanova, Recent advances in multiple emulsions and their application as templates, Curr. Opin. Colloid Interface Sci. 25 (2016) 98-108. https://doi.org/10.1016/j.cocis.2016.07.006.

[52] Y. Chevalier, M.-A. Bolzinger, Emulsions stabilized with solid nanoparticles: Pickering emulsions, Colloids Surf. Physicochem. Eng. Asp. 439 (2013) 23-34. https://doi.org/10.1016/j.colsurfa.2013.02.054.

[53] F.M. Fernandes Barros, C. Chassenieux, M.M. de Souza Lima, L. Benyahia, Structure and rheology during catastrophic phase inversion of Pickering emulsions stabilized with fumed silica particles, Colloids Surf. Physicochem. Eng. Asp. 593 (2020) 124630. https://doi.org/10.1016/j.colsurfa.2020.124630.

[54] C.P. Whitby, R. Parthipan, Influence of particle concentration on multiple droplet formation in Pickering emulsions, J. Colloid Interface Sci. 554 (2019) 315-323. https://doi.org/10.1016/j.jcis.2019.07.017.

[55] M. Tang, T. Wu, X. Xu, L. Zhang, F. Wu, Factors that affect the stability, type and morphology of Pickering emulsion stabilized by silver nanoparticles/graphene oxide nanocomposites, Mater. Res. Bull. 60 (2014) 118-129. https://doi.org/10.1016/j.materresbull.2014.08.019.

[56] F. Groeneweg, W.G.M. Agterof, P. Jaeger, J.J.M. Janssen, J.A. Wieringa, J.K. Klahn, On the Mechanism of the Inversion of Emulsions, Chem. Eng. Res. Des. 76 (1998) 55-63. https://doi.org/10.1205/026387698524596.

[57] P.S. Clegg, J.W. Tavacoli, P.J. Wilde, One-step production of multiple emulsions: microfluidic, polymer-stabilized and particle-stabilized approaches, Soft Matter. 12 (2016) 998-1008. https://doi.org/10.1039/C5SM01663K.

[58] T.G. Fox, P.J. Flory, The glass temperature and related properties of polystyrene. Influence of molecular weight, J. Polym. Sci. $14 \quad$ (1954) 315-319. https://doi.org/10.1002/pol.1954.120147514.

[59] Y.H. Lin, Entanglement and the molecular weight dependence of polymer glass transition temperature, Macromolecules. $23 \quad$ (1990) 5292-5294. https://doi.org/10.1021/ma00227a019.

[60] N. Wang, X.S. Wu, C. Li, M.F. Feng, Synthesis, characterization, biodegradation, and drug delivery application of biodegradable lactic/glycolic acid polymers: I. Synthesis and characterization, J. Biomater. Sci. Polym. Ed. $11 \quad$ (2000) 301-318. https://doi.org/10.1163/156856200743715.

[61] A. Marcilla, M. Beltrán, Mechanisms of plasticizers action, in: G. Wypych (Ed.), Handb. Plast. Third Ed., ChemTec Publishing, 2017: pp. 119-134. https://doi.org/10.1016/B978-1895198-97-3.50007-X.

[62] C.G. Pitt, G. Zhong-wei, Modification of the rates of chain cleavage of poly( $\epsilon$-caprolactone) and related polyesters in the solid state, J. Controlled Release. 4 (1987) 283-292. https://doi.org/10.1016/0168-3659(87)90020-4.

[63] S. Lappe, D. Mulac, K. Langer, Polymeric nanoparticles - Influence of the glass transition temperature on drug release, Int. J. Pharm. 517 (2017) 338-347. https://doi.org/10.1016/j.ijpharm.2016.12.025.

[64] C. Bouissou, J.J. Rouse, R. Price, C.F. van der Walle, The Influence of Surfactant on PLGA Microsphere Glass Transition and Water Sorption: Remodeling the Surface 
Morphology to Attenuate the Burst Release, Pharm. Res. 23 (2006) 1295-1305. https://doi.org/10.1007/s11095-006-0180-2. 
Supporting Material

\title{
Tuning morphology of Pickering emulsions stabilised by biodegradable PLGA nanoparticles:
}

how PLGA characteristics influence emulsion properties

\begin{abstract}
Baptiste Robin ${ }^{1}$, Claire Albert ${ }^{1}$, Mohamed Beladjine ${ }^{1}$, François-Xavier Legrand ${ }^{1}$, Sandrine Geiger ${ }^{1}$, Laurence Moine ${ }^{1}$, Valérie Nicolas ${ }^{2}$, Alexis Canette ${ }^{3}$, Michaël Trichet $^{3}$, Nicolas Tsapis ${ }^{1}$, Florence Agnely ${ }^{1 \dagger}$, Nicolas Huang ${ }^{1 t^{*}}$
\end{abstract}

${ }^{1}$ Université Paris-Saclay, CNRS, Institut Galien Paris-Saclay, 92296, Châtenay-Malabry, France

2 Microscopy facility (MIPSIT), Ingénierie et Plateformes au Service de l'Innovation Thérapeutique- IPSIT- UMS - US31 - UMS3679 (IPSIT), Université Paris-Saclay, ChâtenayMalabry, France

${ }^{3}$ Sorbonne Université, CNRS, Institut de Biologie Paris-Seine (IBPS), Service de microscopie électronique (IBPS-SME), F-75005, Paris

${ }^{\dagger}$ Same contribution

*Corresponding author: N. Huang, nicolas.huang@universite-paris-saclay.fr 


\section{Supporting Material 1: Polymer characterisation}

The characteristics of the PLGA polymers used here to prepare NPs are summarized in the commercial product name, made of three digits and one letter. The first two digits represent the fraction of lactic acid monomer in the polymer chain. In our case, it is 75 as all our polymers are composed of $75 \%$ of lactic acid and $25 \%$ of glycolic acid. The third digit corresponds to the molar mass of the PLGA: the higher this digit, the longer the polymer chain. However, the company did not give any information about the molar mass of the polymer but provided values of inherent viscosity instead. Finally, the letter at the end of the PLGA denomination indicates its ending group. The letter $\mathrm{H}$ stands for acid end group, while the letter $\mathrm{S}$ stands for ester end group.

We characterised all the polymers we used to confirm the information provided by the company. First, each PLGA polymer was characterised by nuclear magnetic resonance ( $\left.{ }^{1} \mathrm{H} N \mathrm{NM}\right)$ (Figure S1.1). These spectra provided information about their LA/GA ratio and end group (Table S1.1). For all the PLGA polymers, the integration value for the d peak (corresponding to the $\mathrm{CH}$ moiety in the LA) was set at 1 . As expected, this resulted in an integration value of $3,14 \pm$ 0.11 for the $\mathrm{c}$ peak (corresponding to the $\mathrm{CH}_{3}$ moiety of $\mathrm{LA}$ ). On all spectra, a value of $0.70 \pm$ 0.01 was found for the e peak (corresponding to the $\mathrm{CH}_{2}$ moiety of $\mathrm{GA}$ ): this is consistent with a 75/25 LA/GA ratio, as given by the supplier. In the case of ester-ending PLGA, two peaks, a and $\mathrm{b}$, were identified, corresponding respectively to the $\mathrm{CH}_{3}$ and the $\mathrm{CH}_{2}$ moieties of the ester end group. Through their integration, the number of carbons composing the ester was evaluated at 8 (for PLGA $753 \mathrm{~S}$ ) and 10 (for PLGA $752 \mathrm{~S}$ ). In the case of acid-ending PLGA, the ester peaks were not present, but a broad peak (a') corresponding to the mobile proton of the acid end group was observed (assignment confirmed by the addition of deuterium oxide, data not shown).

Number-averaged molar mass $\left(M_{n}\right)$, mass-averaged molar mass $\left(M_{w}\right)$ and molar-mass dispersity $\left(\Xi_{M}\right.$, defined as the ratio of $M_{w}$ to $M_{n}$ ) of the polymers were determined by steric exclusion chromatography (SEC) relative to PMMA standards (Table SM1.1). Whatever the polymer end group, the molar masses were two to three times higher for PLGA 753 than for PLGA 752, whether it be the number-averaged $\left(M_{n} \approx 8,000 \mathrm{~g} / \mathrm{mol}\right.$ for PLGA 752 versus $M_{n} \approx 24,000 \mathrm{~g} / \mathrm{mol}$ for PLGA 753) or the weight-averaged molar masses $\left(M_{w} \approx 14,000 \mathrm{~g} / \mathrm{mol}\right.$ for PLGA 752 versus $M_{w} \approx 32,000 \mathrm{~g} / \mathrm{mol}$ for PLGA 753). This was consistent with the inherent viscosity provided by the supplier, that followed the same trend. 


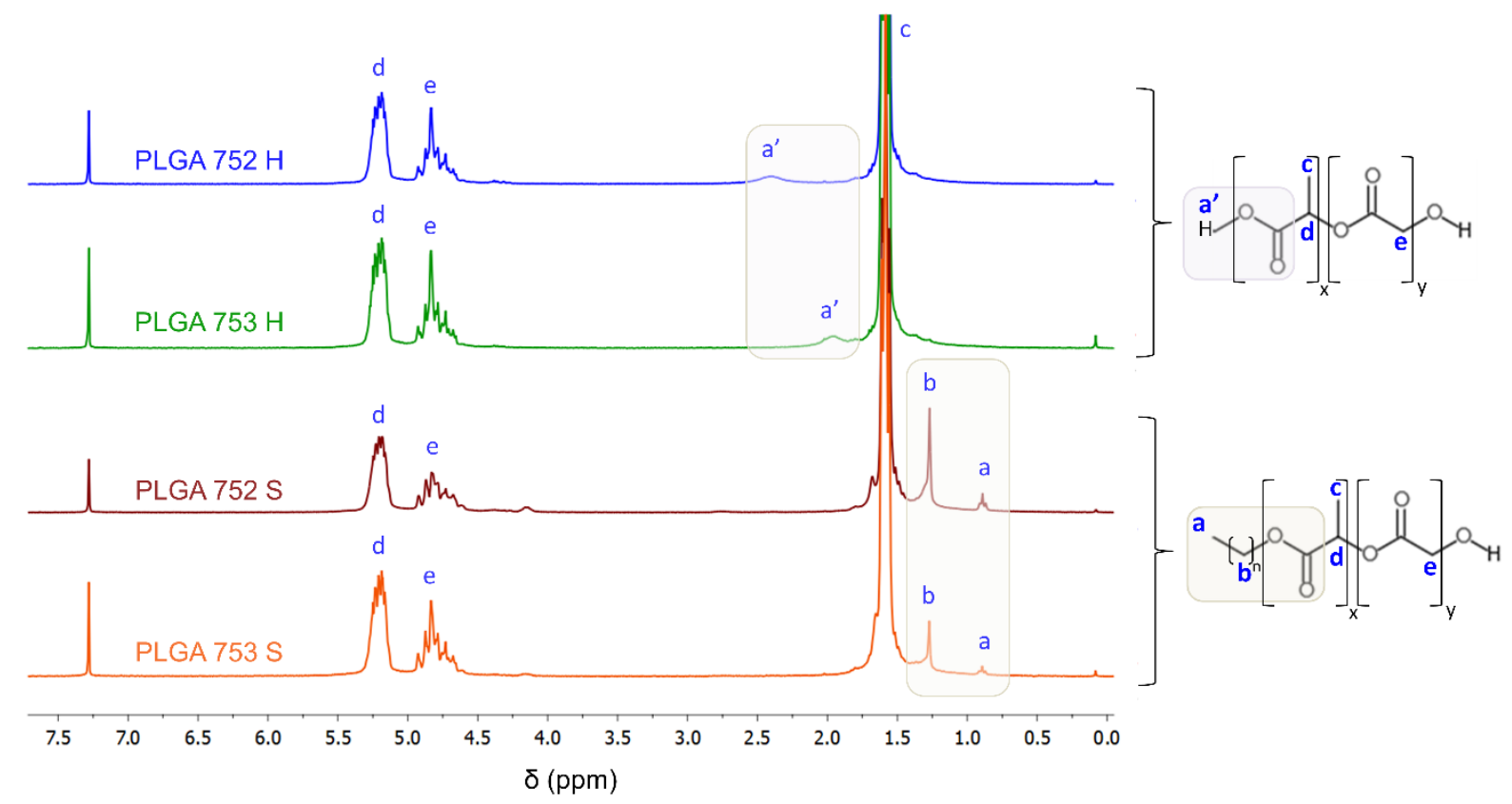

Figure SM1.1: ${ }^{1} \mathrm{H}$ NMR spectra of PLGA polymers of different molar mass and end group

Table SM1.4: Characteristics of polymers, analysed by ${ }^{1} \mathrm{H}$ NMR and SEC

\begin{tabular}{c||cccccc}
\hline $\begin{array}{c}\text { Studied } \\
\text { polymer }\end{array}$ & LA/GA ratio & End group & $\begin{array}{c}\text { Inherent viscosity* }(\mathrm{dL} / \mathrm{g}) \\
25^{\circ} \mathrm{C}, 0.1 \% \mathrm{CHCl}_{3}\end{array}$ & $\mathrm{M}_{\mathrm{n}}(\mathrm{g} / \mathrm{mol})$ & $\mathrm{M}_{\mathrm{w}}(\mathrm{g} / \mathrm{mol})$ & $\Xi_{\mathrm{M}}$ \\
\hline PLGA 752 H & $75 / 25$ & acid & $0.14-0.22$ & 7,000 & 14,000 & 2 \\
PLGA 753 H & $75 / 25$ & acid & $0.32-0.44$ & 23,000 & 32,000 & 1.4 \\
\hline PLGA 753 S & $75 / 25$ & ester C8 & $0.32-0.44$ & 25,000 & 33,000 & 1.3 \\
PLGA 752 S & $75 / 25$ & ester C10 & $0.16-0.24$ & 8,000 & 14,000 & 1.8 \\
\hline
\end{tabular}

*information provided by the supplier 


\section{Supporting Material 2: NP characterisation}

Precisions must be given about the variations of size distribution and $\zeta$-potential of NPs (section 3.1 of the main article). The $\zeta$-potential values varied depending on the PLGA composition. NPs made of acid-ending PLGA $(752 \mathrm{H}$ and $753 \mathrm{H})$ led to a very negative $\zeta$ potential $(-50 \mathrm{mV})$ because of the exposure of the acid end groups at the NP surface. Indeed, the $\mathrm{pK}_{\mathrm{a}}$ of lactic acid and glycolic acid are both around 3.8 [1]. The $\mathrm{pH}$ of the NP suspensions was comprised between 3.5 and 5 (depending on the NP type) which promotes the presence of carboxylate forms, providing a very negative $\zeta$-potential to the NPs [2].

PLGA end group also influenced NP size. The fact that ester-ending PLGA (752 S and 753 S) led to larger NPs compared to acid-ending PLGA $(752 \mathrm{H}$ and $753 \mathrm{H})$ is explained in literature [3]. Indeed, the nucleation-growth mechanism driving the nanoprecipitation is influenced by the presence of charged groups. These latter favour the presence of polymer chains at the interface, reducing the interfacial tension. As low interfacial tension increases nucleation rates and decreases growth and aggregation rates, this led to the formation of more NPs, of smaller size, compared to ester groups. Acid-ending PLGA NPs being more negatively charged, they are logically smaller.

\section{$\underline{\text { References }}$}

[1] Chemical Rubber Company, ed., CRC handbook of chemistry and physics: a readyreference book of chemical and physical data, 84th ed, CRC Press, Boca Raton, 2003.

[2] S.K. Sahoo, J. Panyam, S. Prabha, V. Labhasetwar, Residual polyvinyl alcohol associated with poly (d,I-lactide-co-glycolide) nanoparticles affects their physical properties and cellular uptake, J. Controlled Release. 82 (2002) 105-114. https://doi.org/10.1016/S01683659(02)00127-X.

[3] A. Reisch, A. Runser, Y. Arntz, Y. Mély, A.S. Klymchenko, Charge-Controlled Nanoprecipitation as a Modular Approach to Ultrasmall Polymer Nanocarriers: Making Bright and Stable Nanoparticles, ACS Nano. 9 (2015) 5104-5116. https://doi.org/10.1021/acsnano.5b00214.

[4] D.P. Joshi, Y.L. Lan-Chun-Fung, J.G. Pritchard, Determination of poly(vinyl alcohol) via its complex with boric acid and iodine, Anal. Chim. Acta. 104 (1979) 153-160. https://doi.org/10.1016/S0003-2670(01)83825-3.

[5] C. Albert, N. Huang, N. Tsapis, S. Geiger, V. Rosilio, G. Mekhloufi, D. Chapron, B. Robin, M. Beladjine, V. Nicolas, E. Fattal, F. Agnely, Bare and Sterically Stabilized PLGA Nanoparticles for the Stabilization of Pickering Emulsions, Langmuir. 34 (2018) 13935-13945. https://doi.org/10.1021/acs.langmuir.8b02558. 


\section{Supporting Material 3: Analysis of the tablet surface by AFM}

Atomic force microscopy (AFM) pictures of NP tablets were collected in air at room temperature $\left(22^{\circ} \mathrm{C}\right)$ using a commercial Multimode-8 equipped with a NanoScope $V$ controller from Bruker manufacturer (Bruker, AXS, France). Tablets (prepared as described in section 2.4.3 of the main article) were fixed on magnetic disks directly mounted on top of the AFM scanner. Topographic properties were imaged using the Peak Force quantitative nano mechanical (QNM) property mode with a nanoindentation frequency of $2 \mathrm{kHz}$. PeakForce mode worked with small controlled load forces (around $0.1 \mathrm{nN}$ ) and with deformation depths as small as $1 \mathrm{~nm}$, so damage to the probe or sample was kept minimal. MPP-21100-10 cantilevers (Bruker) were used, with a spring constant of $3 \mathrm{~N} / \mathrm{m}$ and a tip radius between 8 and $10 \mathrm{~nm}$. The scan rate was adjusted in the range of 0.5 to $1 \mathrm{~Hz}$ over selected areas $(5.0 \mu \mathrm{m} \times 5.0 \mu \mathrm{m}$ and $10.0 \mu \mathrm{m} \times 10.0 \mu \mathrm{m})$. Data processing was performed with the WSxM and Bruker softwares. The roughness was characterised using Raparameter (calculated from the Bruker software), which is one of the most commonly used roughness statistics. $R$ a is the arithmetic average of the absolute values of the surface height deviations measured from the mean plan. The mean calculated values corresponded to the average of three values, taken from three images for each type of NP tablets.

Some examples of AFM images of NP tablets are shown in Figure SM3.1. The shape of the NPs remained distinguishable, although they seemed flattened. This allowed us to assume that the tablet surface kept the molecular organization of freeze-dried NPs, making it a representative model to study the surface hydrophobicity of NPs. Moreover, we did not observe deep cracks, or major irregularities of the topography. This was quantified by the $R_{a}$ (Table SM3.1). The average roughness was not higher than the diameter of a NP, as it was comprised between 37 and $121 \mathrm{~nm}$. This low roughness probably did not have influence on the contact angle measured on the NP tablets. In other words, we considered that contact angles measured on NP tablets followed ideal Young's law and did not need to be modelled by Wenzel or Cassie-Baxter equations. Thus, contact angles measured on NP tablets were assumed to be directly related to the chemical composition of the NP surface. 

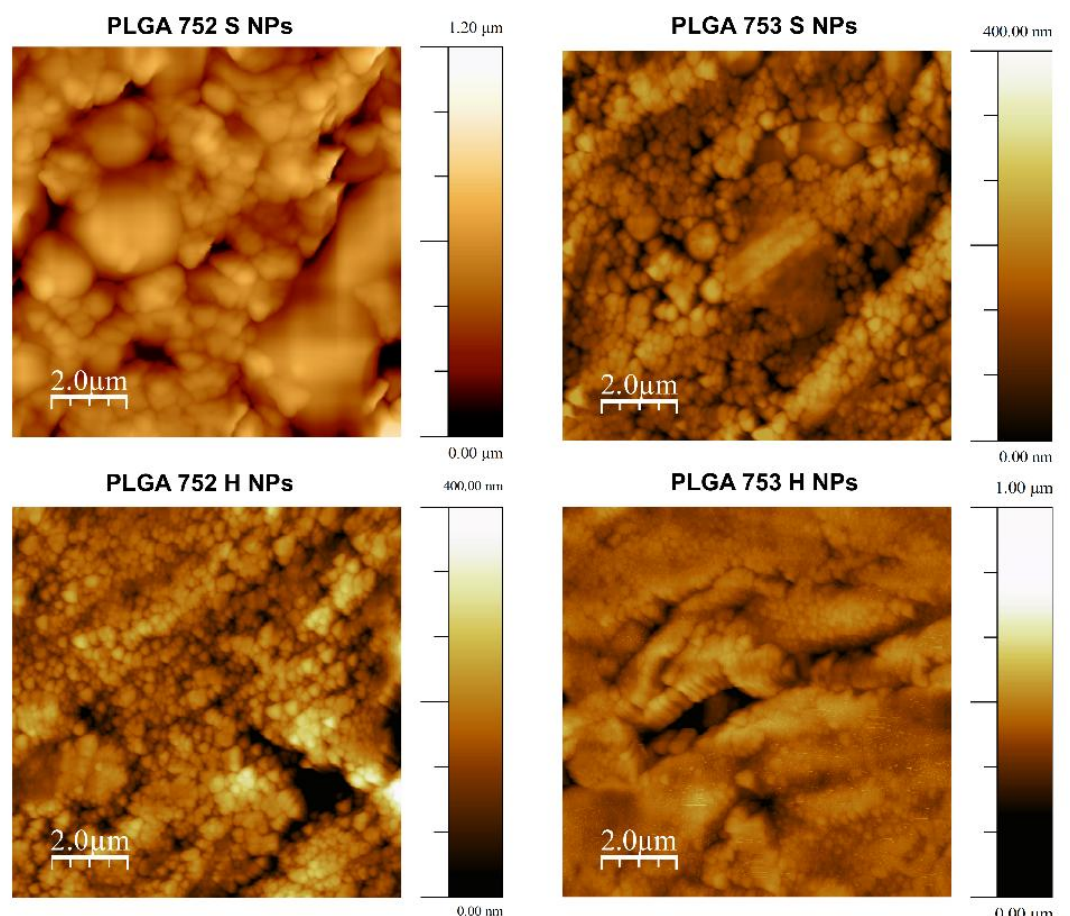

$409.00 \mathrm{nu}$
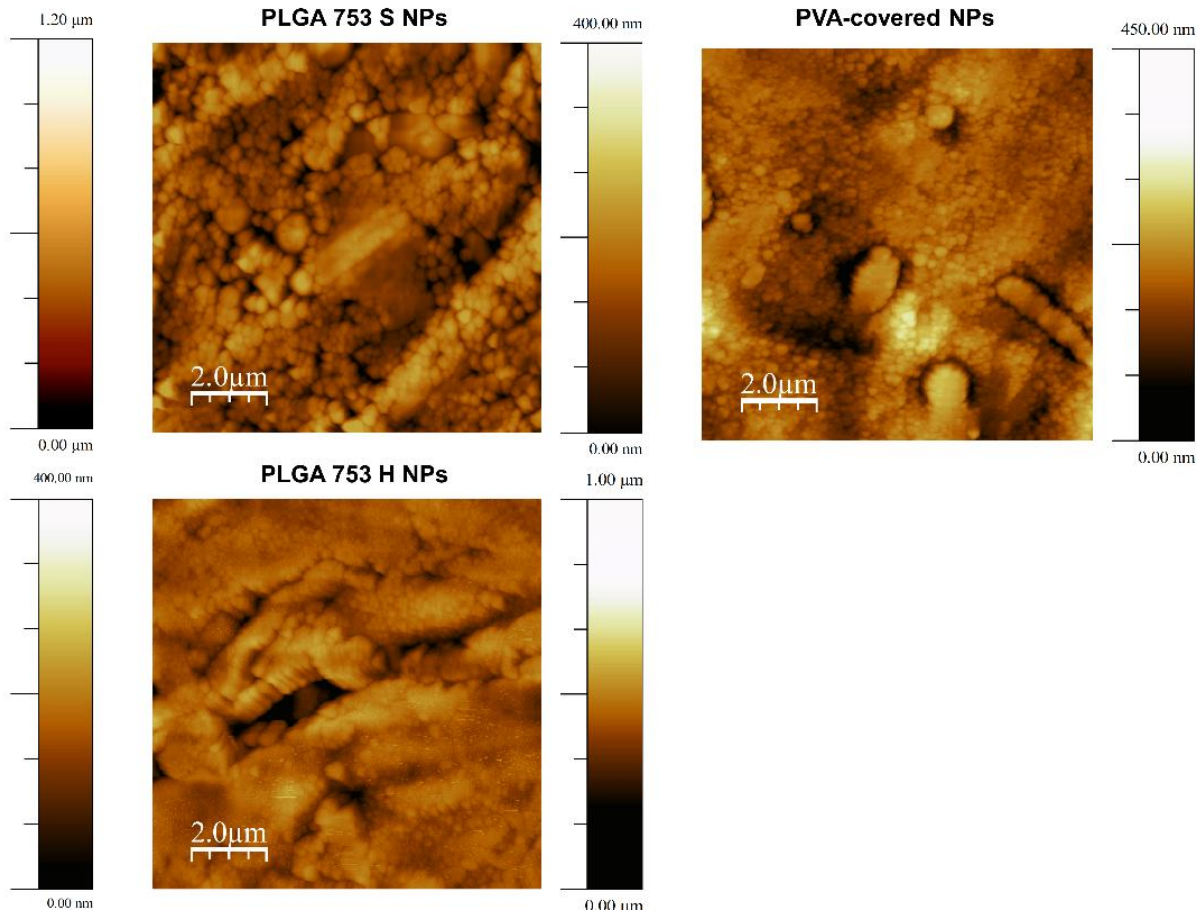

Figure SM3.1: AFM images of the surface of NP tablets, used to measure the contact angle between NPs and a drop of water in air

Table SM3.1: Average roughness of the surface of NP tablets, measured in AFM

\begin{tabular}{c||c}
\hline NP studied & $\mathrm{R}_{\mathrm{a}}(\mathrm{nm})$ \\
& \\
\hline PLGA-PVA 753S & $\begin{array}{c}100 \pm \\
107\end{array}$ \\
\hline PLGA 752 H & $37 \pm 11$ \\
PLGA 753 H & $50 \pm 26$ \\
\hline PLGA 753 S & $83 \pm 56$ \\
PLGA 752 S & $121 \pm 14$ \\
\hline
\end{tabular}




\section{Supporting Material 4: Phase inversion and multiple emulsions}

To determine the oil amount necessary to the phase inversion of emulsions, 5-g emulsions with different water/oil ratios were prepared and characterised as described in the sections 2.5 and 2.6 of the main article. The resulting pictures allowed us to build phase diagrams showed in Figures SM4.1 to SM4.5. The data shown in Table 2 of the main article were extracted from these diagrams. Apart the value of the oil amount necessary to induce the phase inversion, this study showed that all the NPs studied were able to stabilise multiple $\mathrm{W} / \mathrm{O} / \mathrm{W}$ emulsions. According to the literature, several experimental conditions could have favoured that fact.

First, Groeneweg et al. suggested that the formation of inner droplets (called "inclusions") was due to the enclosure of a small volume of continuous phase during the coalescence of two droplets under high shear rate. However, the amount of dispersed phase (here, Miglyol 812N) had to be high enough to allow collision and coalescence between these two droplets [1]. Indeed, we can observe simple O/W emulsions with $10 \%$ of oil, for PLGA-PVA NPs (Figure SM4.1). Multiple W/O/W emulsions started to form with higher amount of oil, for this type of NPs.

After their formation, inclusions can escape from the drops. If the escape rate of inclusions is higher than the formation rate, multiple emulsions might never be observed. To limit the escape of the inclusions, they might be stabilised. In our case, inclusions observed in the multiple emulsions made with PLGA 752 H NPs, PLGA 753 H NPs and PLGA 753 S NPs with 10\% of oil are covered by a NP layer, as revealed in cryoSEM (Figure SM4.6), which explains their stability even after the end of the emulsification. This coverage is possible for two main reasons, according to the literature: (i) contact angles might be close to $90^{\circ}$ in the three phase system, to stabilise both $\mathrm{O} / \mathrm{W}$ and W/O interfaces [2]; and (ii) there is a large excess of NPs available to stabilise the new interface formed during the inclusion [3]. It should be noted that cryoSEM observation of stabilised inclusions could not be done for PLGA-PVA NPs and PLGA 752 S NPs, because the oil amount of the observed emulsions was set at $10 \%$. However, these NPs are able to form multiple emulsions at other oil amounts, as shown in Figures SM4.1 and SM4.5. Some cryoSEM observations could be performed on these multiple emulsions to check if the inclusions they contain were also covered by NPs.

Finally, the formation of multiple emulsions can be a short step preceding the phase inversion to a W/O emulsion. According to Groeneweg et al., a W/O/W emulsion with a fixed composition under constant shear can evolve towards a W/O emulsion. Indeed, if coalescence occurs constantly while inclusions are stabilised and do not escape, an accumulation of inclusions occurs, increasing the effective volume fraction of disperse phase. Up to a critical volume fraction, the dispersed phase becomes the continuous phase: this is the phase inversion [1]. So, the emulsification time is an important parameter governing the production of multiple W/O/W emulsions or W/O emulsions. This assumption was validated for PLGA $753 \mathrm{~S}$, as shown in Figure SM4.7. Indeed, with an oil amount of $20 \%$, we usually observed a W/O emulsion after 2 min of emulsification. But the reduction of the emulsification time to $75 \mathrm{~s}$ prevented the system from inverting, leading to the observation of $\mathrm{W} / \mathrm{O} / \mathrm{W}$ emulsions. Thus, we assumed that the multiple $\mathrm{W} / \mathrm{O} / \mathrm{W}$ emulsions formed under the conditions of our experiments with all the types of 
NPs studied (Figures SM4.1 to SM4.5) could be observed because the emulsification time was not higher than 2 min. With longer times, it could have been inverted.

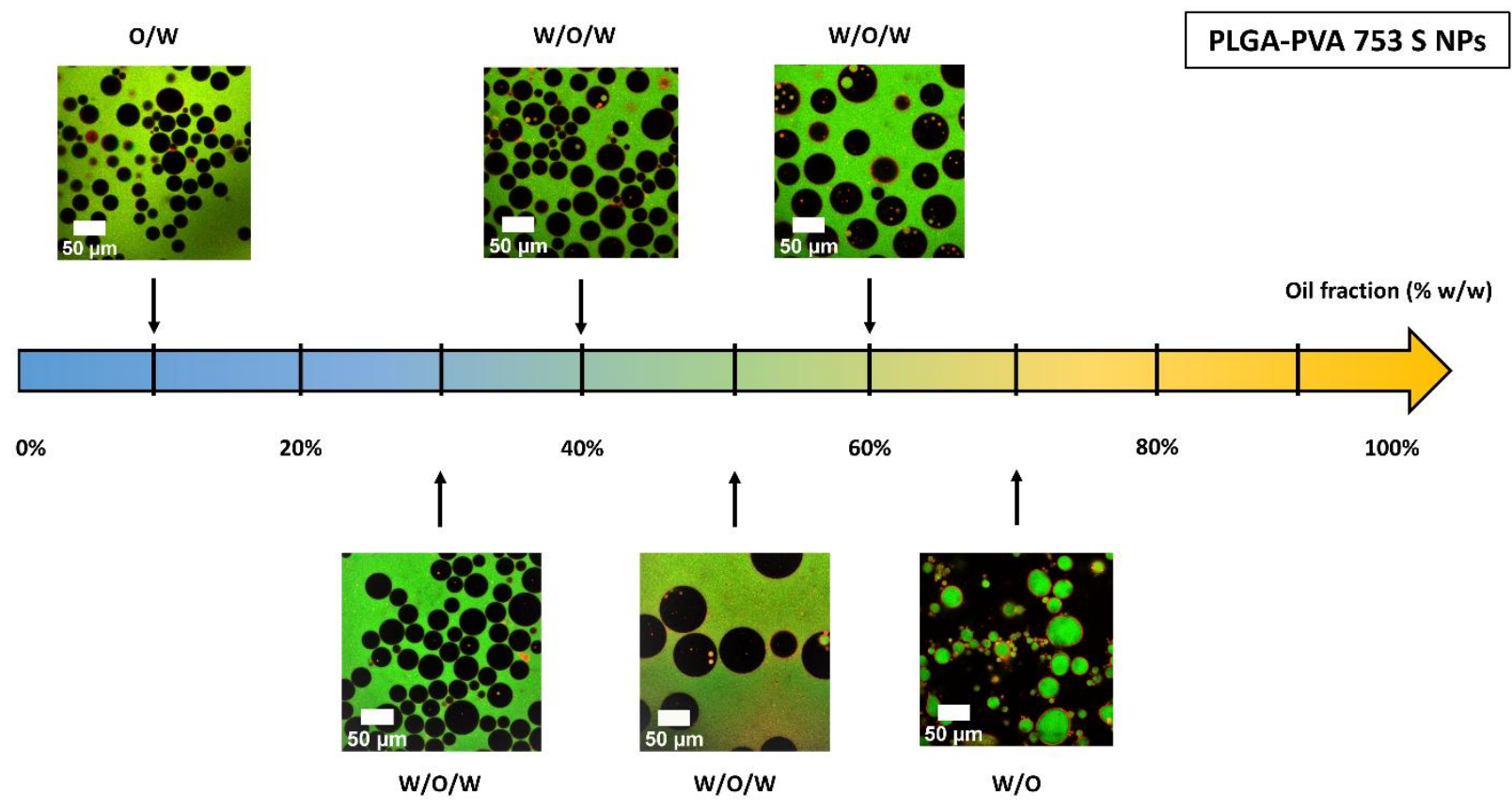

Figure SM4.1: CLSM images of emulsions with various water/oil ratio $(\mathrm{w} / \mathrm{w})$, stabilised by PLGAPVA 753 S NPs. The NPs are red-labelled by PLGA-rhodamine, while the water is green-labelled by calcein. 


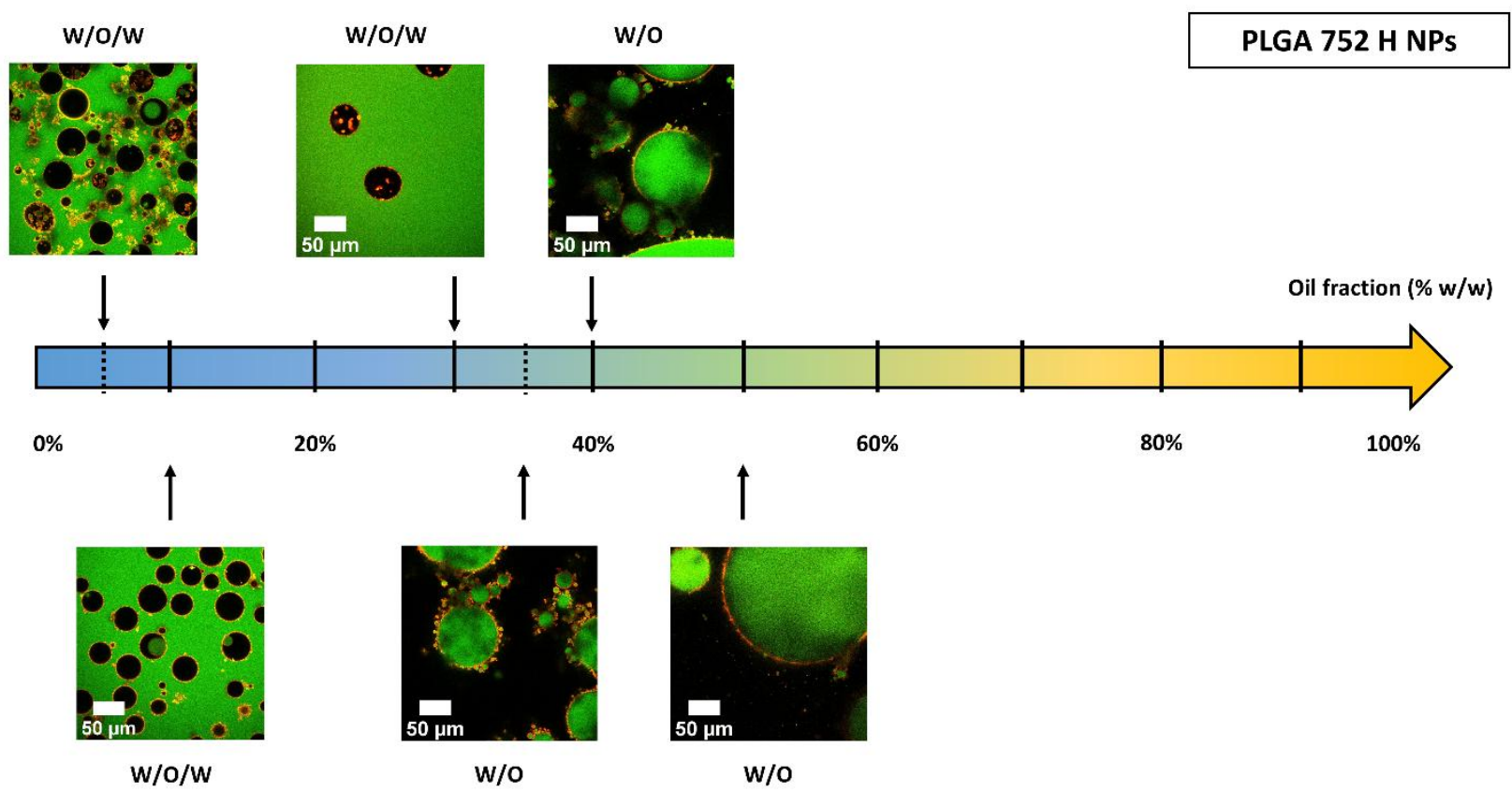

Figure SM4.2: CLSM images of emulsions with various water/oil ratio (w/w), stabilised by PLGA 752 H NPs. The NPs are red-labelled by PLGA-rhodamine, while the water is green-labelled by calcein.

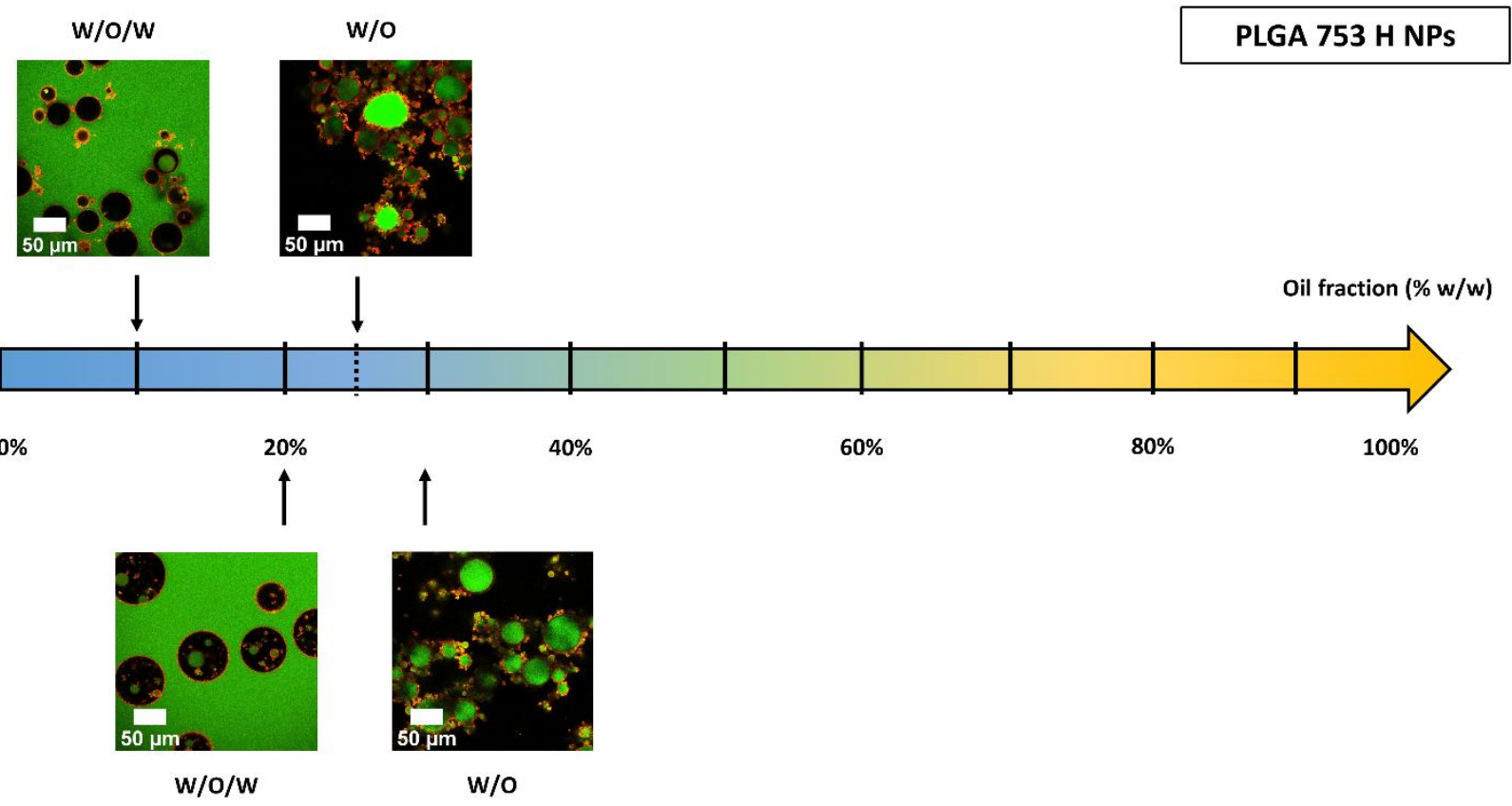

Figure SM4.3: CLSM images of emulsions with various water/oil ratio (w/w), stabilised by PLGA 753 H NPs. The NPs are red-labelled by PLGA-rhodamine, while the water is green-labelled by calcein. 


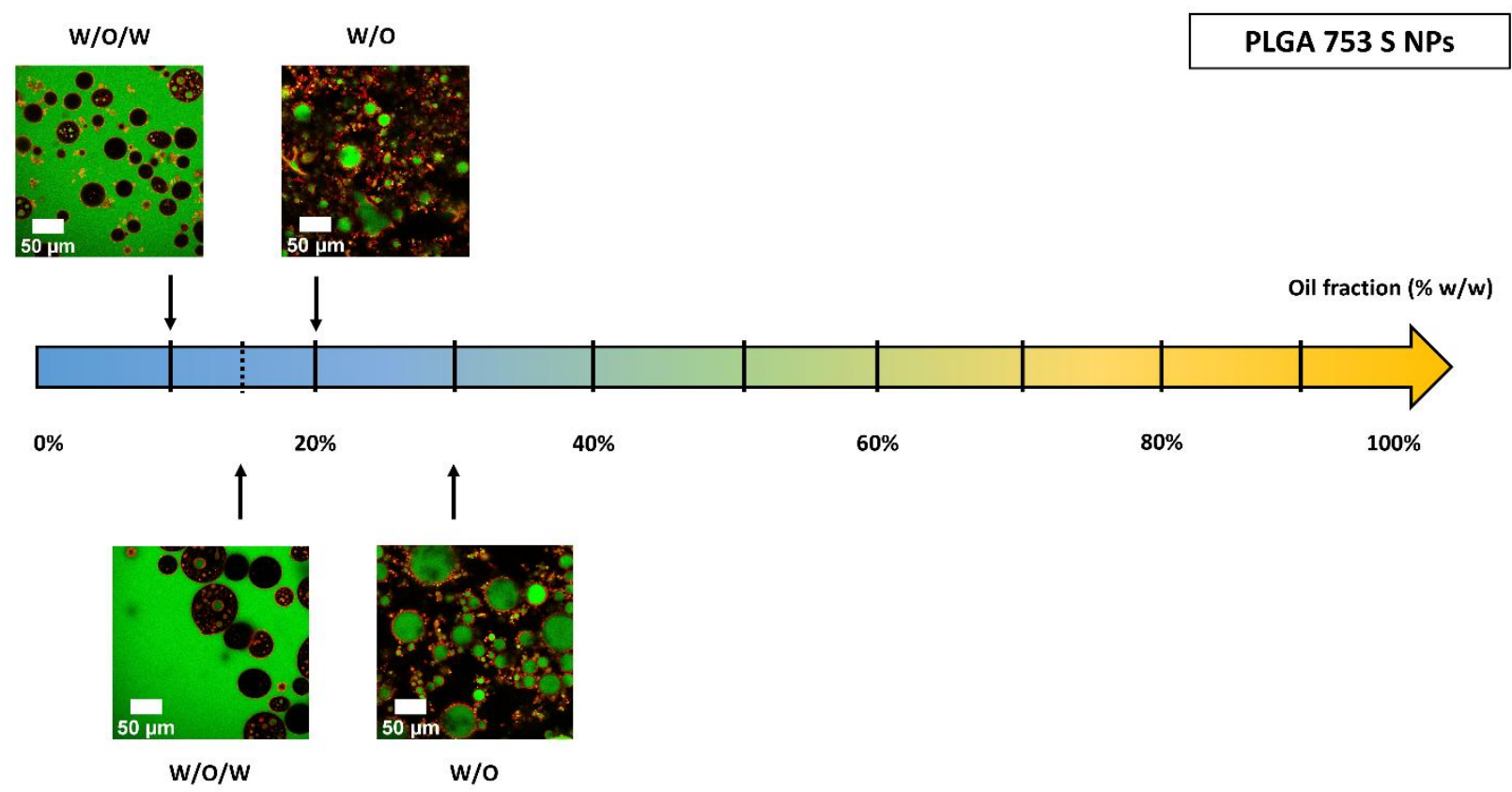

Figure SM4.4: CLSM images of emulsions with various water/oil ratio $(\mathrm{w} / \mathrm{w})$, stabilised by PLGA 753 S NPs. The NPs are red-labelled by PLGA-rhodamine, while the water is green-labelled by calcein.

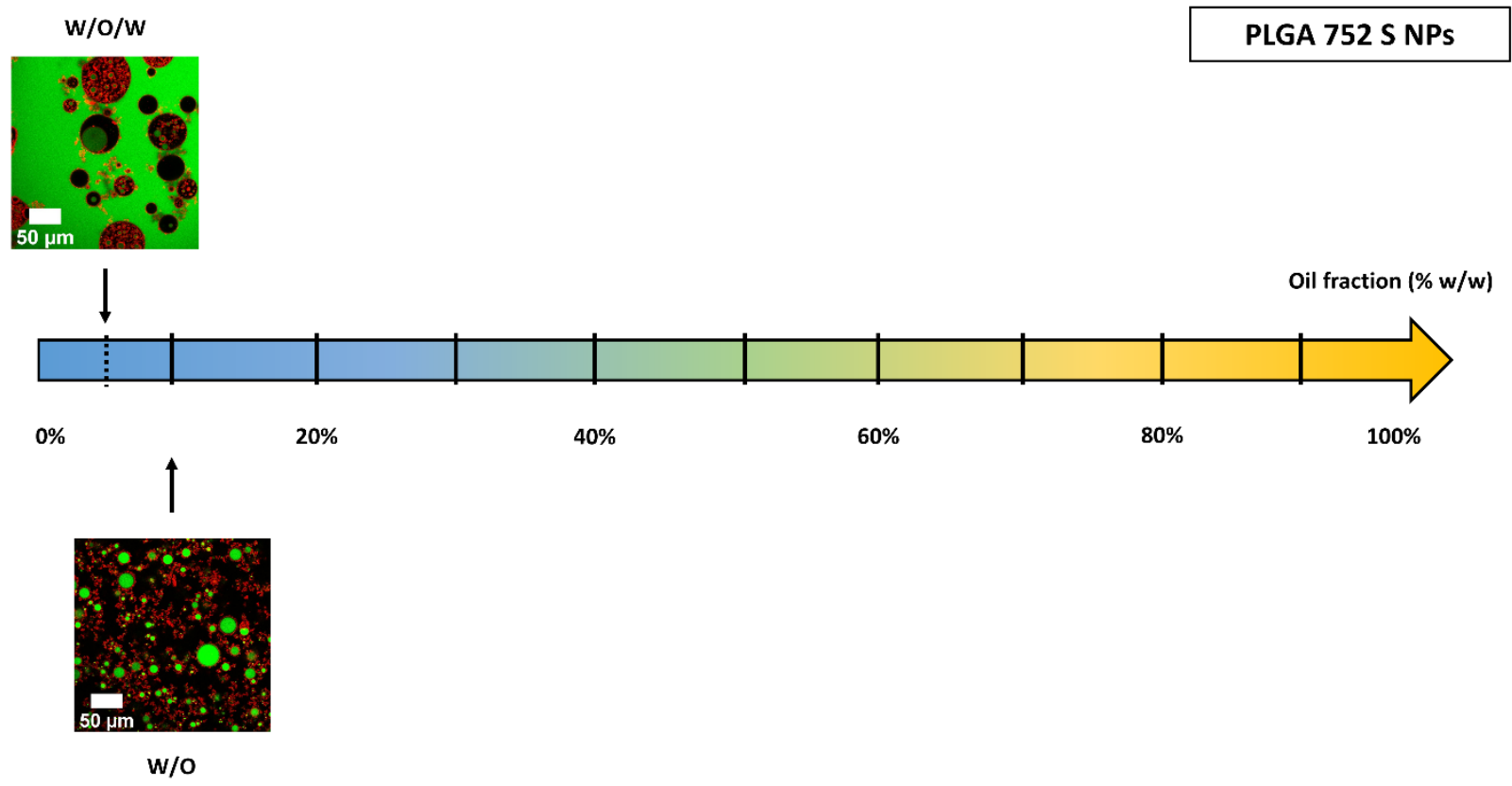

Figure SM4.5: CLSM images of emulsions with various water/oil ratio ( $w / w)$, stabilised by PLGA 752 S NPs. The NPs are red-labelled by PLGA-rhodamine, while the water is green-labelled by calcein. 

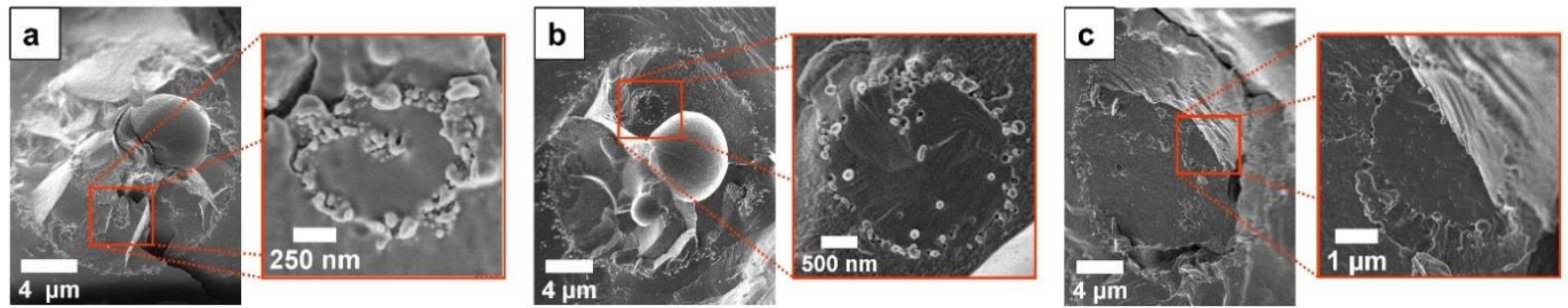

Figure SM4.6: CryoSEM images showing the NP coverage of inner droplets in multiple emulsions prepared with a water/oil ratio of 90/10 $(\mathrm{w} / \mathrm{w})$, few minutes before freezing for observation, and stabilised by: a) PLGA 752 H NPs, b) PLGA 753 H NPs and c) PLGA 753 S NPs

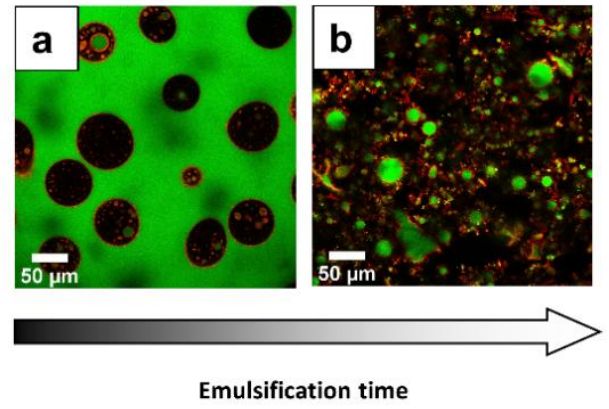

Figure SM4.7: CLSM images of emulsions with a water/oil ratio of $80 / 20(\mathrm{w} / \mathrm{w})$, prepared few minutes before the observation, and stabilised by PLGA 753 S NPs. The emulsification time was set at a) $75 \mathrm{~s}$ and

b) $2 \mathrm{~min}$. The NPs are red-labelled by PLGA-rhodamine, while the water is green-labelled by calcein.

\section{References}

[1] F. Groeneweg, W.G.M. Agterof, P. Jaeger, J.J.M. Janssen, J.A. Wieringa, J.K. Klahn, On the Mechanism of the Inversion of Emulsions, Chem. Eng. Res. Des. 76 (1998) 55-63. https://doi.org/10.1205/026387698524596.

[2] B.P. Binks, P.D.I. Fletcher, B.L. Holt, P. Beaussoubre, K. Wong, Phase inversion of particle-stabilised perfume oil-water emulsions: experiment and theory, Phys. Chem. Chem. Phys. 12 (2010) 11954. https://doi.org/10.1039/c0cp00558d.

[3] C.P. Whitby, R. Parthipan, Influence of particle concentration on multiple droplet formation in Pickering emulsions, J. Colloid Interface Sci. 554 (2019) 315-323. https://doi.org/10.1016/j.jcis.2019.07.017. 


\section{Supporting Material 5: Emulsion stability}

To evaluate emulsion stability, emulsions were prepared with each type of NPs, following the usual procedure described in the section 2.5 of the main article. The water/oil ratio was set at $90 / 10(\mathrm{w} / \mathrm{w})$. The emulsions were stored during 55 days at $20^{\circ} \mathrm{C}$ and protected from light. The destabilization phenomena (creaming, sedimentation, flocculation and coalescence) were monitored using Turbiscan Classic MA 2000 apparatus (Formulaction, France) at different times of the study. The different evolution stages of the emulsion were identified thanks to the profile of the Turbiscan curves [1,2].

The stability was also evaluated at the droplet scale during the 7 first days of the stability study. The droplet size was evaluated overtime by flow imaging microscopy, using Flowcell FC200S+HR apparatus (Occhio, Belgium). Before each analysis, a background calibration was performed on MilliQ water. Emulsions were inverted three times to homogenise them. A fraction of emulsion was collected in the middle of the emulsion and diluted in purified water. For emulsion stabilised by PLGA NP, $300 \mu \mathrm{L}$ of sample were diluted in $700 \mu \mathrm{L}$ of water. Emulsions stabilised with PLGA-PVA NP contained more droplets, and these latter were less aggregated so $50 \mu \mathrm{L}$ of emulsion, diluted in $950 \mu \mathrm{L}$ of water, were enough to obtain statistically good results. The diluted sample was then deposited on the top of the 100- $\mu \mathrm{m}$-thick cell. Flowing through the cell at constant rate, several pictures of the sample (magnified 6 times) were shot. From these pictures, size and shape information were calculated by the software Callisto (Occhio, Belgium). As the droplets were spherical, the "inner diameter" was chosen as a representative diameter. It is defined as the diameter of the largest inscribed circle. Droplet flocs and small unidentified items $(<1 \mu \mathrm{m})$ were removed from the analysed particles, filtering them by their inner diameter. Blur droplets in the background of the pictures were removed too, using a "Luminance RSD" filter. This analysis was performed over 7 days at different times ( 5 minutes, 2 hours, 2 days, 7 days). The selected parameters to monitor the evolution of the droplet size were the number-weighed $d_{50}$ (median of the number-weighed size distribution) and the uniformity coefficient (or Hazen coefficient, representing the dispersity of the size distribution). This latter is defined as the ratio $d_{60} / d_{10}$, measured on the number-weighed size distribution.

First, a diagram, presented in Figure SM5.1, summarises the macroscopic evolution of the five emulsions studied by Turbiscan. As they were all quite fluid (except the one made with PLGA $752 \mathrm{~S} \mathrm{NP}$ ), they all underwent a first step of creaming, lasting between 1.5 to $48 \mathrm{~h}$. Creaming is a reversible instability, only consisting in the migration of the oil droplets upwards, as their density is lower than the density of water. This first result was in good agreement with the microscopic study of emulsions, showing no significant change in the droplet size (Figure SM5.2). Droplets stabilised by bare PLGA NPs remained between 30 to $40 \mu \mathrm{m}$, while droplets stabilised by PVA-covered NPs remained around $20 \mu \mathrm{m}$. The uniformity coefficient was around 2 during all this creaming step, suggesting a polydisperse distribution (as 2 is the threshold above which an emulsion is considered polydisperse).

After the creaming steps, different behaviours were observed. On one hand, emulsions stabilised by bare PLGA $752 \mathrm{HNPs}$, PLGA $753 \mathrm{HNPs}$ or PLGA 753 S NPs showed no macroscopic evolution until the end of the study ( 55 days). This result is corroborated by the 
microscopic study over the 7 first days, showing no evolution of the droplet size between the end of the creaming steps and the seventh day. So, these emulsions were very stable.

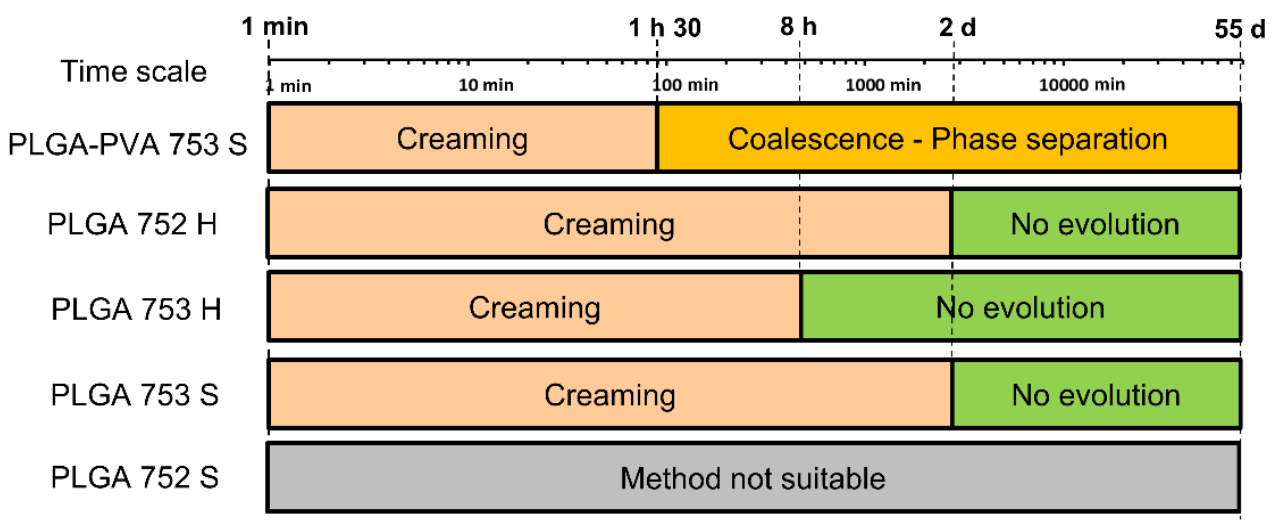

Figure SM5.1: Diagram summarising the evolution of the emulsions as determined by Turbiscan analysis for emulsions stabilised by PLGA-PVA 753 S NPs, PLGA 752 H NPs, 753 H NPs, 753 S NPs or 752 S NPs

On the other hand, the emulsion stabilised by PVA-covered NPs was very different. Indeed, after a 90-min creaming phase, the droplets started to coalesce. An oil phase was observed on top of the emulsions, as an obvious witness of the instability of this emulsion. However, we did not observe any evolution in microscopic behaviour of this emulsion. Droplet size and uniformity coefficient obtained from flow imaging remained stable. We assume that this might be an artefact due to our preparation procedure. After homogenising the emulsion, the large coalesced droplets likely migrated faster towards the top of the emulsion, making them difficult to collect, hence their absence in the analysed samples. Some similar cases were described with Pickering emulsions characterised by laser diffraction for example [3]. This shows how careful we should be when we analyse stability data. Multiscale analysis is necessary to understand the emulsion behaviour in a global way, and to avoid wrong conclusions based on unsuitable technics.
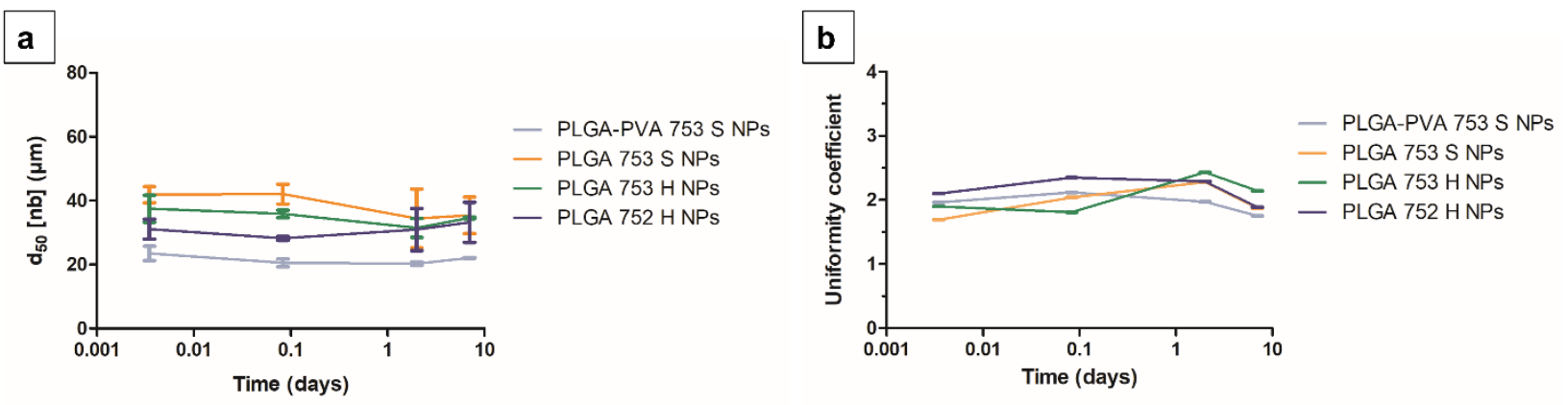

Figure SM5.2: Evolution of the droplet granulometry overtime, for emulsions stabilised by PLGAPVA 753 S NPs (in grey), PLGA 753 S NPs (in orange), PLGA 753 H NPs (in green), PLGA 752 H NPs (in dark blue). The studied parameters were a) the $d_{50}$ of the number-weighed distribution, $b$ ) the uniformity coefficient 
A comment should be given on the emulsion stabilised by PLGA $752 \mathrm{~S}$ bare NP, that remained an exception. Unlike all the other emulsions, this one could not be analysed by Turbiscan and flow imaging microscopy, because of its texture and opacity. The droplet mean diameter was

estimated after 7 days, by a manual measurement on 300 droplets on images of CLSM, using the software Fiji [4]. The estimated size was around $17 \mu \mathrm{m}$ after 7 days, with a uniformity coefficient of 2.25, which meant the emulsion was polydisperse. However, this result must be considered with caution, as it is measured on images of CLSM. Indeed, this technic allows the imaging of a very thin slice of material. In our conditions, the focal planes do not correspond to the equator of all the drops. So, the result presented here is a simple estimation, and the actual drop size might have been underestimated. A Z-stacking followed by a Maximum Intensity Projection are necessary to measure it correctly. Finally, a visual control of the emulsion over 55 days did not show any evolution: the emulsion seemed to remain stable. As discussed previously, a multiscale analysis should be performed to assess the stability. A microscopic monitoring of the droplet size would be better to conclude with certainty about the stability of this emulsion. However, images obtained by optical microscopy are difficult to analyse, as the solid emulsion is not transparent.

\section{$\underline{\text { References }}$}

[1] J. Liu, X. Huang, L. Lu, M. Li, J. Xu, H. Deng, Turbiscan Lab® Expert analysis of the biological demulsification of a water-in-oil emulsion by two biodemulsifiers, J. Hazard. Mater. 190 (2011) 214-221. https://doi.org/10.1016/j.jhazmat.2011.03.028.

[2] O. Mengual, G. Meunier, I. Cayré, K. Puech, P. Snabre, TURBISCAN MA 2000: multiple light scattering measurement for concentrated emulsion and suspension instability analysis, Talanta. 50 (1999) 445-456. https://doi.org/10.1016/S0039-9140(99)00129-0.

[3] H. Lim, M. Jo, C. Ban, Y.J. Choi, Interfacial and colloidal characterization of oil-in-water emulsions stabilized by interface-tunable solid lipid nanoparticles, Food Chem. 306 (2020) 125619. https://doi.org/10.1016/j.foodchem.2019.125619.

[4] J. Schindelin, I. Arganda-Carreras, E. Frise, V. Kaynig, M. Longair, T. Pietzsch, S. Preibisch, C. Rueden, S. Saalfeld, B. Schmid, J.-Y. Tinevez, D.J. White, V. Hartenstein, K. Eliceiri, P. Tomancak, A. Cardona, Fiji: an open-source platform for biological-image analysis, Nat. Methods. 9 (2012) 676-682. https://doi.org/10.1038/nmeth.2019. 


\section{Supporting Material 6: Graphical determination of $T_{g(0)}$}

An example of thermogram is given in Figure SM6.1, for PLGA $753 \mathrm{~S}$. The three dash lines represent the tangent lines of the curve at the baseline (before and after the glass transition) and at the inflection point of the glass transition step. The first crossover point defines the onset of the glass transition ( $T_{g}$ onset), while the second one defines its end ( $T_{g}$ end). The midpoint is midway between these two crossover points, and the corresponding temperature is the " $\mathrm{T}_{g}$ midpoint". This $\mathrm{T}_{\mathrm{g}}$ midpoint was measured at several scan rate, and an extrapolation by linear regression led to the $T_{g}$ midpoint at zero rate, as described in the section 2.6.4 of the main article. This value, called $\mathrm{T}_{\mathrm{g}(0)}$, was the one we used to compare the samples.

Besides, it can be noticed that the glass transition signal was weaker for PLGA NPs in emulsion, compared to the dry PLGA. This was attributed to the lower PLGA concentration, considering the whole emulsion.

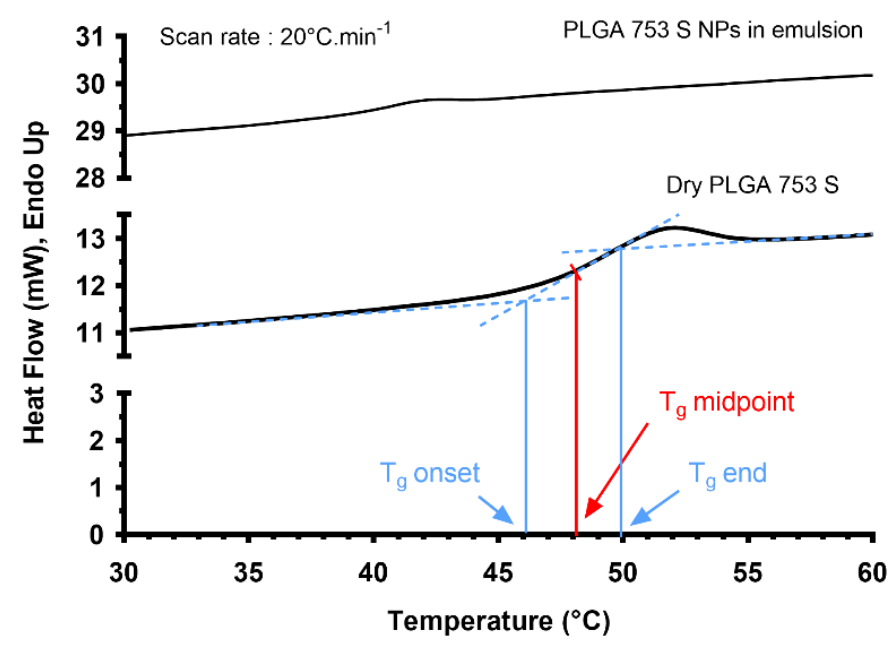

Figure SM6.14: Example of thermograms of PLGA $753 \mathrm{~S}$, obtained at a scan rate of $20^{\circ} \mathrm{C} \cdot \mathrm{min}^{-1}$, in two different conditions: the lower curve corresponds to the dry PLGA, the upper curve corresponds to the PLGA NPs in the emulsion. The dash lines on the lower curve are the tangent lines of the curve at the baseline (before and after the glass transition) and at the inflection point of the glass transition step, and are used to determine the midpoint $\mathrm{T}_{\mathrm{g}}$ (glass transition temperature at the scan rate $20^{\circ} \mathrm{C} \cdot \mathrm{min}^{-1}$ ). 